\title{
Heat Transfer in Turbulent Supercritical Carbon Dioxide Flowing in a Heated Horizontal Tube
}

Douglas A. Olson

David Allen

U.S. DEPARTMENT OF COMMERCE

Technology Administration

Process Measurements Division

Chemical Science and Technology Laboratory

National Institute of Standards

and Technology

Gaithersburg, MD 20899-0001

QC

100

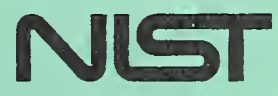

.056

110.6234

1998 



\section{Heat Transfer in Turbulent Supercritical Carbon Dioxide Flowing in a Heated Horizontal Tube}

Douglas A. Olson

David Allen

U.S. DEPARTMENT OF COMMERCE Technology Administration

Process Measurements Division Chemical Science and Technology Laboratory National Institute of Standards and Technology

Gaithersburg, MD 20899-0001

September 1998

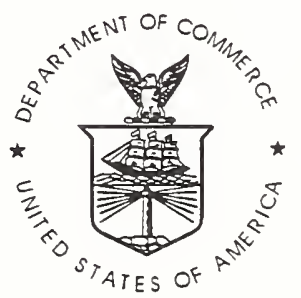

U.S. DEPARTMENT OF COMMERCE William M. Daley, Secretary

TECHNOLOGY ADMINISTRATION Gary R. Bachula, Acting Under Secretary for Technology

NATIONAL INSTITUTE OF STANDARDS

AND TECHNOLOGY

Raymond G. Kammer, Director 
2

(2) 


\section{CONTENTS}

Nomenclature

Abstract

1. Introduction 2

2. Description of experimental apparatus 3

2.1 Flow loops 3

2.2 Test section 4

2.3 Instrumentation 5

3. Description of experiments and analysis techniques 5

3.1 Experiments conducted and procedure 5

3.2 Analysis to determine heat transfer coefficient 7

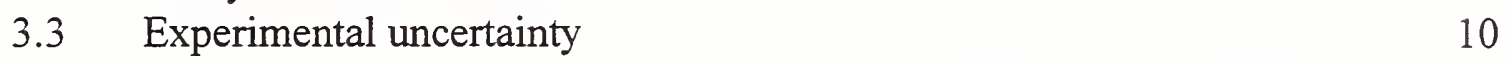

4. Results of experiments 10

4.1 Effects of experimental parameters on heat transfer coefficient $\quad 10$

4.2 Comparisons of the data with constant property predictions 11

4.3 Comparisons of the data with supercritical correlations 12

$\begin{array}{lll}\text { 5. Summary and conclusions } & 14\end{array}$

\begin{tabular}{ll} 
6. & References \\
\hline
\end{tabular} 


\section{LIST OF TABLES}

Table 1. Summary of test section parameters and experimental conditions.

Table 2. Summary of standard uncertainties for measured parameters and combined standard uncertainties for calculated parameters.

Table 3. Comparison of measured Nusselt number to values predicted by Petukhov-Gnielinski (constant property) correlation and to Krashnochekov-Protopopov (supercritical, constant heat flux) correlation. 


\section{LIST OF FIGURES}

Figure 1. Properties of carbon dioxide on the $8.36 \mathrm{MPa}$ isobar from $0{ }^{\circ} \mathrm{C}$ to $70{ }^{\circ} \mathrm{C}$. $\quad 20$

Figure 2. Carbon dioxide flow loop of the NIST supercritical heat transfer facility. 21

Figure 3. Water flow loop of the NIST supercritical heat transfer facility. 22

$\begin{array}{ll}\text { Figure 4. Counterflow heat exchanger test section. } & 23\end{array}$

Figure 5. $\quad \mathrm{CO}_{2}$ heat transfer coefficient $(h)$ as a function of mass flux $(W)$ for several 24 values of pressure $\left(P / P_{c}\right)$ at a heat flux $\left(Q_{A}\right)$ of $20 \mathrm{~kW} / \mathrm{m}^{2}$ to $22 \mathrm{~kW} / \mathrm{m}^{2}$.

Figure 6. $\quad \mathrm{CO}_{2}$ heat transfer coefficient $(h)$ as a function of mass flux $(W)$ for several 25 values of pressure $\left(P / P_{c}\right)$ at a heat flux $\left(Q_{A}\right)$ of $30 \mathrm{~kW} / \mathrm{m}^{2}$ to $35 \mathrm{~kW} / \mathrm{m}^{2}$.

Figure 7. $\quad \mathrm{CO}_{2}$ heat transfer coefficient $(h)$ as a function of mass flux $(W)$ for several 26 values of pressure $\left(P / P_{c}\right)$ at a heat flux $\left(Q_{A}\right)$ of $47 \mathrm{~kW} / \mathrm{m}^{2}$ to $52 \mathrm{~kW} / \mathrm{m}^{2}$.

Figure 8. $\quad \mathrm{CO}_{2}$ heat transfer coefficient $(h)$ as a function of mass flux $(W)$ for several 27 values of pressure $\left(P / P_{c}\right)$ at a heat flux $\left(Q_{A}\right)$ of $59 \mathrm{~kW} / \mathrm{m}^{2}$ to $65 \mathrm{~kW} / \mathrm{m}^{2}$.

Figure 9. $\quad \mathrm{CO}_{2}$ heat transfer coefficient $(h)$ as a function of mass flux $(W)$ for several values of heat flux $\left(Q_{A}\right)$ at a pressure of $P / P_{c}=1.05$.

Figure 10. $\quad \mathrm{CO}_{2}$ heat transfer coefficient $(h)$ as a function of mass flux $(W)$ for several values of heat flux $\left(Q_{A}\right)$ at a pressure of $P / P_{c}=1.77$.

Figure 11. Comparison of measured $\mathrm{CO}_{2}$ heat transfer coefficient $(h)$ to that predicted by Petukhov-Gnielinski correlation, as a function of mass flux $(W)$, for $Q_{A}=20 \mathrm{~kW} / \mathrm{m}^{2}$ to $22 \mathrm{~kW} / \mathrm{m}^{2}, P / P_{c}=1.05$, and $P / P_{c}=1.77$.

Figure 12. Comparison of measured $\mathrm{CO}_{2}$ heat transfer coefficient $(h)$ to that predicted by Petukhov-Gnielinski correlation, as a function of mass flux $(W)$, for $Q_{A}=59 \mathrm{~kW} / \mathrm{m}^{2}$ to $65 \mathrm{~kW} / \mathrm{m}^{2}, P / P_{c}=1.05$ and $P / P_{c}=1.77$.

Figure 13. Comparison of Nusselt number predicted by Krashnoschekov-

Protopopov correlation $\left(N u_{K P}\right)$ to the measured value $\left(N u_{\text {meas }}\right)$ for all experimental data. $\pm 7 \%$ deviation lines shown for comparison. 
Nomenclature

\begin{tabular}{|c|c|c|}
\hline $\begin{array}{l}A_{f} \\
A_{h t}\end{array}$ & $\begin{array}{l}= \\
=\end{array}$ & $\begin{array}{l}\text { flow normal area for } \mathrm{CO}_{2} \\
\text { heat transfer area between the water and carbon dioxide, based on the inner tube } \\
\text { inside radius }\end{array}$ \\
\hline$c_{p}$ & $=$ & specific heat \\
\hline D & $=$ & diameter \\
\hline$f$ & $=$ & friction factor \\
\hline$h_{\mathrm{CO}_{2}}$ & $=$ & carbon dioxide heat transfer coefficient \\
\hline$h_{\mathrm{H}^{2} \mathrm{O}}$ & $=$ & water heat transfer coefficient \\
\hline & $=$ & specific enthalpy at location $\mathrm{L}$ or 0 for water or $\mathrm{CO}_{2}$ \\
\hline$k$ & $=$ & thermal conductivity \\
\hline$k_{s s}$ & $=$ & thermal conductivity of the stainless steel of the tube \\
\hline$L$ & $=$ & heat transfer length \\
\hline$m_{\mathrm{CO} 2}$ & $=$ & carbon dioxide mass flow rate \\
\hline$m_{\mathrm{H} 20}$ & $=$ & water mass flow rate \\
\hline$n$ & $=$ & exponent in Krashnoschekov-Protopopov correlation \\
\hline $\mathrm{Nu}$ & $=$ & Nusselt number $=h D / k$ \\
\hline$N u_{K P}$ & $=$ & Nusselt number predicted by Krashnoschekov-Protopopov correlation \\
\hline$N u_{\text {meas }}$ & $=$ & measured Nusselt number \\
\hline$N u_{P G}$ & $=$ & Nusselt number predicted by Petukhov-Gnielinski correlation \\
\hline$P$ & $=$ & pressure \\
\hline$P_{c}$ & $=$ & critical pressure \\
\hline $\operatorname{Pr}$ & $=$ & Prandtl number $=\mu c_{f} / k$ \\
\hline$Q$ & $=$ & $\begin{array}{l}\text { total heat transferred between the water and carbon dioxide over the entire heat } \\
\text { exchanger length }\end{array}$ \\
\hline$Q_{A}$ & $=$ & heat flux $=Q / A_{h t}$ \\
\hline$Q_{\mathrm{CO} 2}$ & $=$ & heat absorbed by the carbon dioxide in heat exchanger \\
\hline$Q_{e r r}$ & $=$ & error in heat balance \\
\hline$Q_{\mathrm{H} 2 \mathrm{O}}$ & $=$ & heat released by the water in heat exchanger \\
\hline$Q_{\text {loss }}$ & $=$ & heat loss from water through tube insulation to the room \\
\hline$r_{i}$ & $=$ & inner tube inside radius \\
\hline$r_{o}$ & $=$ & inner tube outside radius \\
\hline $\operatorname{Re}$ & $=$ & Reynolds number $=\rho \mathrm{VD} / \mu$ \\
\hline$T$ & $=$ & temperature \\
\hline$T_{b}$ & $=$ & $\begin{array}{l}\text { bulk fluid temperature in Krashnoschekov-Protopopov correlation, taken as } \\
\text { average of } \mathrm{CO}_{2} \text { inlet and outlet temperatures }\end{array}$ \\
\hline$T_{c}$ & $=$ & critical temperature \\
\hline$T_{m}$ & $=$ & temperature for which the specific heat is a maximum for the given pressure \\
\hline$T_{w}$ & $=$ & wall temperature at the location of bulk temperature $T_{b}$ \\
\hline$U$ & $=$ & overall heat transfer coefficient \\
\hline$U h_{C}$ & $=$ & combined standard uncertainty in $\mathrm{CO}_{2}$ heat transfer coefficient \\
\hline & $=$ & ombined standard uncertainty in water heat transfer coefficien \\
\hline
\end{tabular}


$U \Delta T_{L M}=\quad$ combined standard uncertainty in log mean temperature difference

$U N u_{\text {meas }}=\quad$ combined standard uncertainty in measured Nusselt number

$U \mathrm{Pr}_{\mathrm{CO} 2}=\quad$ combined standard uncertainty in $\mathrm{CO}_{2}$ Prandtl number

$U Q_{C O 2}=$ combined standard uncertainty in $\mathrm{CO}_{2}$ heat flow

$U Q_{H_{2} O}=$ combined standard uncertainty in water heat flow

$U Q_{e r r}=$ combined standard uncertainty in heat balance error

$U R e_{C O 2}=$ combined standard uncertainty in $\mathrm{CO}_{2}$ Reynolds number

$V \quad=\quad$ velocity

$W \quad=\quad$ mass flux $=m / A_{f}$

$\Delta P=$ pressure drop

$\Delta T_{L}=\mathrm{T}_{\mathrm{H} 2 \mathrm{O}}-\mathrm{T}_{\mathrm{CO} 2}$ at the "L" location of the heat exchanger, which is the $\mathrm{CO}_{2}$ outlet and the water inlet

$\Delta T_{L M}=\quad \log$ mean temperature difference

$\Delta T_{0}=\mathrm{T}_{\mathrm{H} 2 \mathrm{O}}-\mathrm{T}_{\mathrm{CO}_{2}}$ at the "0" location of the heat exchanger, which is the $\mathrm{CO}_{2}$ inlet and the water outlet

$\mu \quad=\quad$ viscosity

$\rho=$ density 



\title{
Heat Transfer in Turbulent Supercritical Carbon Dioxide \\ Flowing in a Heated Horizontal Tube
}

\author{
Douglas A. Olson \\ David Allen \\ Process Measurements Division \\ National Institute of Standards and Technology \\ Gaithersburg, MD 20899
}

\begin{abstract}
We report measurements of heat transfer coefficients of flowing supercritical carbon dioxide (7.38 $\mathrm{MPa}$ critical pressure, $31.1{ }^{\circ} \mathrm{C}$ critical temperature) in a heated horizontal tube. The tube was $10.9 \mathrm{~mm} \mathrm{ID}$, was heated over $274 \mathrm{~cm}$, and had an unheated entrance section of $55.9 \mathrm{~cm}$. Heating was accomplished by flowing hot water countercurrent to the carbon dioxide in an annular gap between the inner tube (12.7 $\mathrm{mm} \mathrm{OD})$ and an outer tube (16.6 $\mathrm{mm} \mathrm{ID).} \mathrm{This} \mathrm{set} \mathrm{a}$ convective boundary condition similar to what would be encountered in a shell-in-tube heat exchanger. Operating pressure was varied from 7.8 $\mathrm{MPa}$ to $13.1 \mathrm{MPa} ; \mathrm{CO}_{2}$ mass flow rate was varied from $1.0 \mathrm{~kg} / \mathrm{min}$ to $5.1 \mathrm{~kg} / \mathrm{min}$; heating was varied from $1150 \mathrm{~W}$ to $6180 \mathrm{~W}$; and $\mathrm{CO}_{2}$ inlet temperature was varied from $-1.7{ }^{\circ} \mathrm{C}$ to $32.7^{\circ} \mathrm{C}$. The Reynolds number range at the $\mathrm{CO}_{2}$ average temperature was 34300 to 154600 . At the highest pressure tested, the measured Nusselt numbers agreed to the constant property Petukhov-Gnielinski correlation for turbulent flow in a tube to within $6.6 \%$, except when Reynolds number was less than 72000 and the heat flux was greater than $47 \mathrm{~kW} / \mathrm{m}^{2}$. As the pressure was reduced toward the critical pressure, the measured Nusselt numbers diverged from the constant property correlation. At these lower pressures, conditions of high mass flow and low heat flow enhanced the heat transfer, while conditions of low mass flow and high heat flow degraded the heat transfer. The Krashnoschekov-Protopopov correlation for supercritical flow, developed for conditions of a constant heat flux boundary condition when buoyancy is negligible, predicted the measured Nusselt numbers to within one standard deviation of $3.0 \%$ (range of $-6.5 \%$ to $+10.1 \%$ ).
\end{abstract}

Key words: apparatus; carbon dioxide; counterflow heat exchanger; heat transfer; horizontal tubes; supercritical flow; turbulent flow

Partial support for this work came from US Army CECOM RD\&E Center under MIPR JC8BR.

Certain commercial equipment, instruments, materials, or software are identified in this paper to foster understanding. Such identification does not imply recommendation or endorsement by NIST, nor does it imply that the materials or equipment identified are necessarily the best available for the purpose. 


\section{Introduction}

The application motivating this work is the proposed use of carbon dioxide as a "natural refrigerant" in various refrigeration, air conditioning, and heat pump cycles (Lorentzen and Pettersen, 1993). Supercritical fluids have also become increasingly important as alternative fluids in other modern technologies such as destruction of organic wastes, chemical synthesis and extraction, and precision cleaning. Specifically, the U.S. Army is interested in the feasibility of developing a carbon dioxide-based Environmental Control Unit (ECU) (Manzione, 1998), which is a combination heat pump and air conditioner. Carbon dioxide offers much reduced ozone depletion potential and global warming potential than chlorofluorocarbons and hydrofluorocarbons; it is also non-toxic and non-flammable. However, system designs will have to be adapted to the characteristics of carbon dioxide, and the cycle efficiency will be important in determining whether the systems will be commercially viable. In contrast to cycles with conventional refrigerant fluids, the pressure in a carbon dioxide cycle will be above the critical during the heat rejection process. Hence a supercritical cooling operation would replace the gas condenser.

In this work we have measured the heat transfer performance of supercritical carbon dioxide flowing in a horizontal tube, information which will be important in evaluating the Army heat pump cycle and other supercritical heat transfer processes. (The carbon dioxide critical pressure, $P_{c}$, is $7.38 \mathrm{MPa}$ and the critical temperature, $T_{c}$ is $31.1^{\circ} \mathrm{C}$ ). In this experiment, carbon dioxide at a supercritical pressure flowed through a $10.9 \mathrm{~mm}$ ID tube and was heated by water flowing countercurrent to it over $2.74 \mathrm{~m}$ of its length. The flow of $\mathrm{CO}_{2}$ was turbulent throughout the tube. The direction of the heat transfer was opposite to the heat pump application (heating instead of cooling). Results of the present experiments with heating should be evaluated with future experiments on cooling to develop a comprehensive description of the heat exchanger performance. The primary experimental parameters which we varied were system pressure, flow rate, and heating rate. We report how the heat transfer varies with the experimental parameters, and compare the data to correlations in the literature.

Heat transfer in supercritical fluids has been studied by many investigators, as summarized by Hall and Jackson (1978). Supercritical flows are complex because of the rapid variations in transport and thermophysical properties which occur near the critical point (Fig. 1; data from Span and Wagner, 1996, and Vesovic et al., 1990). When heat transfer measurements are compared to what would be expected for a constant property fluid with these fluid properties, the heat transfer can be enhanced or degraded, depending on flow or heating conditions which have no effect in a constant property fluid. Certain sets of conditions can also produce buoyancy in the flow, which can further enhance or degrade the heat transfer. Heat transfer correlations, which take into account the rapidly varying properties, have had some success in predicting the experimental measurements if conditions with significant buoyancy are eliminated from the data set. In almost all of the past work, the heat transfer boundary condition at the wall of the tube has been one of constant heating, which was generated by resistive heating in the tube wall. The only exception is the work of Walisch et al. (1997) who tested heating with a constant wall 
temperature. Heat exchangers in carbon dioxide heat pump cycles will have convective boundary conditions, with either air or water exchanging heat with the carbon dioxide. Our present measurements are the first comprehensive data set which has the convective boundary conditions in supercritical flow.

\section{Description of experimental apparatus}

\section{$2.1 \quad$ Flow Loops}

Experiments were conducted with the counterflow heat exchanger test section placed in the heat transfer facility shown schematically in Figs. 2 and 3. The facility consists of two closed fluid loops, one for carbon dioxide and one for water, which join at the test section. The flow loops were filled with instrument grade carbon dioxide ( $99.99 \%$ purity) and deionized water, respectively.

Flow is circulated through the carbon dioxide loop by a centrifugal pump with a magneticallycoupled drive, which has a maximum capacity of $72 \mathrm{~L} / \mathrm{min}$ (at no pressure drop). A variable speed drive on the motor of the pump was used to control the flow rate. Carbon dioxide was added to the system with a $500 \mathrm{~mL}$ syringe pump, which also controlled the operating pressure. Flow rate was measured with a coriolis flow meter. After exiting the flow control valve, the carbon dioxide entered a "pre-cooler" heat exchanger which lowered its temperature to the desired test section inlet temperature, about $0{ }^{\circ} \mathrm{C}$ at the minimum. The pre-cooler consisted of $5.5 \mathrm{~m}$ of $12.7 \mathrm{~mm}$ OD tubing, with a $60 / 40$ ethylene glycol/water mixture flowing countercurrent to the carbon dioxide inside a $25 \mathrm{~mm}$ OD tube. The temperature of the carbon dioxide in the precooler was controlled by pumping the ethylene glycol/water coolant to it from a recirculating cooler ( $3 \mathrm{~kW}$ capacity at $0{ }^{\circ} \mathrm{C}$, controllable temperature). Upon exiting the pre-cooler, the carbon dioxide flow entered the test section, which was a counterflow heat exchanger with hot water flowing in the annular gap outside of the tube containing the carbon dioxide. After leaving the test section, the carbon dioxide was cooled down to ambient temperature by another counterflow heat exchanger, referred to as the "gas cooler", utilizing laboratory cold water as the cold sink. This heat exchanger also contained $5.5 \mathrm{~m}$ of $12.7 \mathrm{~mm}$ OD tubing for the heat exchange area. The carbon dioxide then reentered the pump. The system volume was about $2 \mathrm{~L}$. The tubing connecting the test section outlet to the gas cooler was $19 \mathrm{~mm}$ OD 316 stainless steel, and the tubing from the pre-cooler to the test section inlet connection was a teflon-lined, stainless-steel braided hose. All of the remaining tubing, including the heat exchangers, was 12.7 $\mathrm{mm}$ OD 316 stainless steel. All components in the flow loop were rated to a pressure of 13.8 $\mathrm{MPa}$ or higher.

The hot water flow loop was similar in design to the carbon dioxide flow loop. The water was circulated with a turbine pump, rated for $19 \mathrm{~L} / \mathrm{min}$ at $40 \mathrm{~m}$ of head. The flow rate was controlled with the pump bypass valve and flow control valve. Flow rate was also measured with a coriolis flow meter. After exiting the flow control valve, the water entered an in-line electric water heater which contained four immersion heaters capable of up to $9 \mathrm{~kW}$ of heating. The heaters were 
powered by a 208VAC, $50 \mathrm{amp} \mathrm{SCR} \mathrm{controlled} \mathrm{power} \mathrm{supply.} \mathrm{The} \mathrm{temperature} \mathrm{of} \mathrm{the} \mathrm{water}$ entering the test section was controlled by setting the power to the heaters. The carbon dioxide in the test section cooled the water. An air-operated piston pump was used to fill the flow loop and maintain pressure when the system was operating. A back-pressure regulator prevented overpressure of the system due to thermal expansion of the water. The hot water loop was rated to pressures up to $2100 \mathrm{kPa}$, and was operated at $700 \mathrm{kPa}$ to prevent boiling at the maximum water temperature $\left(120^{\circ} \mathrm{C}\right)$. The tubing was $19.1 \mathrm{~mm} \mathrm{OD}, 316$ stainless steel except for the water heater, which was $25 \mathrm{~mm}$ OD 316 stainless steel.

The hot water loop was insulated with at least $1.3 \mathrm{~cm}$ of fiberglass pipe insulation. The carbon dioxide loop, including the heat exchangers, was insulated with $1.3 \mathrm{~cm}$ of neoprene insulation.

\subsection{Test section}

The experimental test section is shown in Fig. 4. It was a counterflow heat exchanger consisting of a $12.7 \mathrm{~mm}$ OD, $10.9 \mathrm{~mm}$ ID inner tube mounted concentric to a $19.1 \mathrm{~mm} \mathrm{OD}, 16.6 \mathrm{~mm}$ ID outer tube. Carbon dioxide flowed from left-to-right inside the inner tube, and water flowed from right-to-left in the annular space between the two tubes (as per Fig. 4). The tubes were mounted at both ends in O-ring compression fittings which sealed the carbon dioxide and permitted axial movement due to thermal expansion. These fittings were coupled to swaged fittings in which the flow loop inlet and outlet tubing was connected. The length of the inner tube was $348 \mathrm{~cm}$. The first $55.9 \mathrm{~cm}$ of tubing was not surrounded by the outer tube, and hence there was no heat transfer. The outer tube, from centerline to centerline of the connection fittings, extended over the next $274.3 \mathrm{~cm}$ of the inner tube. The final $17.8 \mathrm{~cm}$ of the inner tube length also was unheated. The length-to-diameter ratio of the entrance section was 51 (based on the inner tube inner diameter), and the length-to-diameter ratio of the heated section was 251.

The inlet and outlet temperatures of the carbon dioxide and the water to the test section were measured in thermowells (made from a commercially available $3 / 4$ inch " $T$ " fitting) which permitted the insertion of the thermometers and allowed the fluid to flow past the thermometers. The test section outlet thermowells were located a minimum of $15 \mathrm{~cm}$ from the last $90^{\circ}$ bend to the test section, which provided sufficient tube length to mix the fluids to a uniform temperature. Pressure taps were located in the carbon dioxide flow loop at the thermowells. Pressure taps were located in the water flow loop a short distance upstream of the test section inlet and downstream of the outlet. The inlet pressure of both loops was connected to absolute pressure transducers, and the pressure difference between the inlets and outlets was measured with differential pressure transducers. The entire test section was mounted on a rigid aluminum Ibeam. Slotted holes with teflon shims provided axial movement of the test section relative to the I-beam, which resulted from thermal expansion. The test section was insulated with $1.3 \mathrm{~cm}$ thick fiberglass pipe insulation, as were all the thermowells, thermometers, and connecting tubing from the flow loops. 


\subsection{Instrumentation}

We measured the mass flow rate, test section inlet temperature, test section outlet temperature, test section inlet pressure, and test section differential pressure for both the carbon dioxide and water sides of the test section. Both of the mass flow rates were measured with coriolis mass flow meters. The carbon dioxide flow meter had a range of $0 \mathrm{~kg} / \mathrm{min}$ to $10 \mathrm{~kg} / \mathrm{min}$, with a manufacturer's stated relative uncertainty of $\pm 0.15 \%$ of reading, $\pm 0.68 \mathrm{~kg} / \mathrm{h}$ zero stability. The water flow meter had a range of $0 \mathrm{~kg} / \mathrm{min}$ to $30 \mathrm{~kg} / \mathrm{min}$, with a manufacturer's stated relative uncertainty of $\pm 0.10 \%$ of reading, $\pm 0.163 \mathrm{~kg} / \mathrm{h}$ zero stability. (For this and other manufacturer's stated uncertainties, we assume the values given are normal distributions and that they have about a $95 \%$ "confidence interval". Hence the "standard uncertainty" is $1 / 2$ the stated value. See Taylor and Kuyatt [1994] for a detailed description of the NIST uncertainty policy).

We measured fluid temperatures with platinum resistance thermometers, $6.4 \mathrm{~mm}$ diameter and 15 $\mathrm{cm}$ long. The probes were calibrated by the manufacturer and had a combined repeatability and hysteresis uncertainty of $\pm 0.05^{\circ} \mathrm{C}$. The probe measuring the carbon dioxide inlet temperature was immersed to a depth of $5.1 \mathrm{~cm}$; the remaining probes were immersed to a depth of $7.6 \mathrm{~cm}$. Self-heating and stem conduction errors were calculated to be less than $\pm 0.001{ }^{\circ} \mathrm{C}$. The carbon dioxide pressure at the test section inlet was measured with a quartz crystal pressure transducer with a $41 \mathrm{MPa}$ full scale range. The combined repeatability and hysteresis uncertainty of the transducer was $\pm 4.1 \mathrm{kPa}$. Water absolute pressure, water differential pressure, and carbon dioxide differential pressure were measured with variable-reluctance pressure transducers. These transducers each had a combined repeatability, linearity, and hysteresis uncertainty of $\pm 0.25 \%$ of full scale; or an absolute uncertainty of $5200 \mathrm{~Pa}, 860 \mathrm{~Pa}$, and $86 \mathrm{~Pa}$, respectively for the water absolute pressure, water differential pressure, and carbon dioxide differential pressure.

Signals from the thermometers and variable reluctance pressure transducers were multiplexed through an automated scanner and measured with a digital voltmeter. Signals from the flowmeters were measured with a frequency counter. The signal from the quartz crystal pressure transducer was converted to an ASCII character string by the manufacturer's electronics. Relay switching transients and voltmeter $\mathrm{A} / \mathrm{D}$ conversion introduced negligible uncertainty in the measured quantities. Measurement of the signals was controlled by a personal computer. Raw signals and converted parameters were stored on the hard drive. Some of the parameters were displayed on the video monitor to assist in monitoring and operating the experiment. Heat transfer performance parameters were calculated at the completion of the experiments.

3. Description of experiments and analysis techniques

\subsection{Experiments conducted and procedure}

Six sets of experiments were conducted and their conditions are summarized in Table 1. For each of the six sets, the carbon dioxide pressure was fixed at a constant value. Within each set, carbon dioxide flow rate was varied, as was the amount of heat transferred from the water to the 
carbon dioxide. The first set of experiments was an exploratory operation of the facility to understand some of the conditions attainable and to learn how to control the system parameters. Sets $2,3,4$, and 6 were systematic variations of the flow rate and heating rate, each with 5 flow settings and 4 heating settings ( 20 independent settings with one repeat). At each of the data sets $2,3,4,5$, and 6 we also kept the average of the inlet and outlet temperatures for the carbon dioxide approximately constant. Once a setting was achieved, the instruments were scanned and signals stored multiple times (usually 11). All of the measured and calculated values for each scan of the instruments, each experimental setting, can be found as Excel 97 files on the diskette in the back cover on the report. Altogether we achieved 105 experimental settings and sampled 1115 data points. Measured parameters are listed first, followed by calculated performance parameters, and finally standard uncertainties of the most important parameters. For data set 1 , we had not yet installed the pressure transducer to measure the water pressure drop, so it was estimated based on the water flowrate. For the first 10 settings of data set 6 , the carbon dioxide pressure drop was not measured, and it too was estimated based on the flow rate and density.

We filled the carbon dioxide loop in a consistent manner to achieve a high purity of carbon dioxide. Beginning with air at atmospheric pressure in the system, the loop was pressurized with carbon dioxide gas at the saturation pressure of the supply bottles (about 5.7 $\mathrm{MPa}$ ). This mixture of air and carbon dioxide was vented down to a pressure slightly above atmospheric, preventing back-filling with air. The procedure of filling to the carbon dioxide pressure and venting to atmosphere was performed a minimum of three times. Assuming uniform mixing of the initial charge and the added carbon dioxide during each fill, this reduced the air concentration to a volume fraction of less than $1 \times 10^{-6}$. After the fourth fill of carbon dioxide gas, we filled the syringe pump with liquid carbon dioxide from a bottle containing a dip tube. The pump dispensed the liquid into the flow loop. The syringe pump was re-filled from the bottle and the liquid dispensed into the loop until the loop pressure began to increase, indicating all the vapor space was filled with liquid. System pressure was set by using the syringe pump in a constant pressure mode. Prior to circulating the carbon dioxide and starting heat transfer, the syringe pump was set at about half-full. This allowed it to both dispense and withdraw fluid as the specific volume of carbon dioxide in the flow loop changed due to temperature changes.

To generate heat exchange between the water and carbon dioxide in the heat exchanger test section, both circulating pumps were turned on. The temperature of the water was increased by turning on and adjusting the power to the water heaters. Heat was removed from the carbon dioxide and its temperature was adjusted by: (1) turning on the lab cold water flow to the gas cooler; and (2) setting the temperature of the recirculating cooler which pumped coolant to the pre-cooler. The four major independent parameters which allowed setting the conditions for an experiment were the hot water heater power, the recirculating cooler temperature, the carbon dioxide flow rate, and the carbon dioxide pressure. Carbon dioxide pressure was set and controlled by the syringe pump. The carbon dioxide flow rate was fixed by setting the frequency of variable speed drive on the centrifugal pump. We controlled the heater power and the recirculating cooler temperature until the carbon dioxide inlet temperature and heat transferred were at the desired values. 
Achieving a new steady setting after any of the four parameters were changed required about 15 min. Large changes in temperature required more time, and small temperature changes or small flow rate changes required less time. We defined this stability as a condition when the changes of the experimental parameters or measured quantities with respect to time were small enough so that negligible errors were introduced into the calculated performance parameters $(<0.1 \%)$. Flow and pressure steady state occurred within seconds of changing the set point, whereas thermal steady state required temperatures of the hot water heater, recirculating cooler, and test section to stabilize. Thermal stability was indicated by observing the temperature changes at the fluid thermometers. A drift rate of $0.1^{\circ} \mathrm{C} / \mathrm{min}$ was low enough to introduce negligible error in the performance parameters.

\subsection{Analysis to determine heat transfer coefficient}

We sought to characterize the heat transfer performance of the supercritical carbon dioxide in such a way that it could be systematically evaluated as experimental conditions varied. Also, we desired to compare the performance to other work reported in the literature. The heat exchanger test section had three major modes of heat transfer: convection from the hot water to the inner wall; radial conduction through the tube wall; and convection from the inner tube to the carbon dioxide. Axial conduction in the tube and two fluids was insignificant. Conduction out the insulation to the ambient room was a few percent and was accounted for in calibration. Through analysis of the data, we separated out the carbon dioxide heat transfer as follows.

Heat transfer in a counterflow heat exchanger can be expressed by the "log mean temperature difference" equation which defines the overall heat transfer coefficient, $U$ (Rohsenow and Choi, 1961):

$$
\begin{aligned}
Q & =U A_{h t} \Delta T_{L M} \\
\Delta T_{L M} & =\frac{\Delta T_{L}-\Delta T_{0}}{\ln \frac{\Delta T_{L}}{\Delta T_{0}}}
\end{aligned}
$$

\footnotetext{
Here, $Q=$ total heat transferred between the water and carbon dioxide over the entire heat exchanger length;

$A_{h t}=$ heat transfer area between the water and carbon dioxide, based on the inner tube inside radius;

$U=$ overall heat transfer coefficient;

$T=$ temperature, either water $\left(\mathrm{H}_{2} \mathrm{O}\right)$ or carbon dioxide $\left(\mathrm{CO}_{2}\right)$;

$\Delta T_{L M}=\quad \log$ mean temperature difference;

$\Delta T_{L}=T_{\mathrm{H} 2 \mathrm{O}}-T_{\mathrm{CO}_{2}}$ at the " $\mathrm{L}$ " location of the heat exchanger, which is the $\mathrm{CO}_{2}$ outlet and the water inlet; and

$\Delta T_{0}=\mathrm{T}_{\mathrm{H} 2 \mathrm{O}}-\mathrm{T}_{\mathrm{CO}_{2}}$ at the " 0 " location of the heat exchanger, which is the $\mathrm{CO}_{2}$ inlet and the water outlet.
} 
If the overall heat transfer coefficient is constant throughout the heat exchanger, then Eq. (1) can be derived by integrating the local differential heat flux equation from end to end. Because the transport properties of the carbon dioxide are temperature dependent, the local carbon dioxide heat transfer coefficient will vary in the heat exchanger, and $U$ defined in Eq. (1) will not always equal the local value.

$U$ can be further decoupled into the carbon dioxide convection, tube conduction, and water convection components through the assumption of linear addition of the heat transfer modes:

$$
\frac{1}{U}=\frac{1}{h_{\mathrm{CO} 2}}+\frac{r_{i}}{k_{s s}} \ln \frac{r_{o}}{r_{i}}+\frac{r_{i}}{r_{o}} \frac{1}{h_{\mathrm{H}_{2} \mathrm{O}}}
$$

where $\mathrm{h}_{\mathrm{CO} 2}=$ carbon dioxide heat transfer coefficient;

$r_{i} \quad=$ inner tube inside radius;

$k_{s s} \quad=$ thermal conductivity of the stainless steel of the tube;

$r_{o} \quad=$ inner tube outside radius; and

$h_{H 2 O}=$ water heat transfer coefficient.

The tube radius multipliers account for the different heat transfer area for the three terms. We note that Eq. (2) defines both $\mathrm{h}_{\mathrm{CO}_{2}}$ and $\mathrm{h}_{\mathrm{H}_{2} \mathrm{O}}$ as "average" coefficients that are a single value for the entire tube length. In order to determine $\mathrm{h}_{\mathrm{CO}_{2}}$ as a function of position along the tube, we would need to know the heat flux as a function of position, or the specific enthalpy of either the water or carbon dioxide as a function of position.

We calculated $Q$ from the measurements of the heat absorbed by the flowing carbon dioxide and the heat released by the water:

$$
\begin{aligned}
& Q=Q_{\mathrm{CO}_{2}}=m_{\mathrm{CO}_{2}}\left(i_{L}-i_{0}\right)_{\mathrm{CO}_{2}}, \\
& Q=Q_{\mathrm{H}_{2} \mathrm{O}}=m_{\mathrm{H}_{2} \mathrm{O}}\left(i_{L}-i_{0}\right)_{\mathrm{H}_{2} \mathrm{O}}-Q_{\text {loss }},
\end{aligned}
$$

where $m_{\mathrm{CO} 2}=$ carbon dioxide mass flow rate (measured);

$m_{\mathrm{H} 2 \mathrm{O}}=$ water mass flow rate (measured);

$i=$ specific enthalpy at location $\mathrm{L}$ or 0 for water or $\mathrm{CO}_{2}$; and

$Q_{\text {loss }}=$ heat loss from water through tube insulation to the room.

The specific enthalpy was calculated from thermodynamic equations of state for the water and carbon dioxide at the measured temperature and pressure, $P$ :

$$
i=i(T, P) \text {. }
$$


The equation of state of Span and Wagner (1996) was used for the carbon dioxide, and the NIST Steam Tables were used for water (Gallagher and Haar, 1988). $Q_{\text {loss }}$ was measured as a function of water temperature by operating the water flow loop without carbon dioxide cooling $\left(Q_{H 2 O}=0\right.$ in Eq. (4)). It ranged from 0 to $6 \%$ of $Q$.

The value of $h_{H 2 O}$ was measured in the apparatus prior to performing the experiments of this report, by testing the heat exchanger with cold water in the inner tube and hot water in the annular gap. $h_{H_{2} O}$ was a function of water flow rate and temperature, which was accounted for in its experimentally derived correlation equation. To determine $h_{\mathrm{CO}_{2}}$ at each test point, the heat flow was calculated from the measured temperatures, pressures, and flow rates using Eqs. (3), (4), and (5). The average of the $Q_{\mathrm{H}_{2} \mathrm{O}}$ and $Q_{\mathrm{CO}_{2}}$ was used in Eq. (1) along with the measured temperatures to calculate $U$. The value of $h_{\mathrm{CO}_{2}}$ was then calculated from Eq. (2) by subtracting the tube conduction and water convection terms from $U$.

In the results which follow in Sec. 4 , we present the carbon dioxide heat transfer coefficient, $h_{C O 2}$, as a function of the average heat flux and the carbon dioxide mass flux. Their definitions are:

$$
\begin{aligned}
& Q_{A}=Q / A_{h t}=\text { heat flux; } \\
& W=m / A_{f}=\text { mass flux. }
\end{aligned}
$$

We also calculated the dimensionless heat transfer coefficient, that is the Nusselt number $(\mathrm{Nu})$, along with the Reynolds number $(R e)$ and Prandtl number $(P r)$ for the carbon dioxide at each test condition. These dimensionless parameters are used in correlations of the data.

$$
\begin{aligned}
& N u=\frac{h D}{k} ; \\
& R e=\frac{\rho V D}{\mu} ; \\
& P r=\frac{\mu c_{p}}{k} ;
\end{aligned}
$$

$$
\text { where } \begin{aligned}
k & =\text { thermal conductivity; } \\
V & =\text { velocity; } \\
\rho & =\text { density; } \\
c_{p} & =\text { specific heat; and } \\
\mu & =\text { viscosity. }
\end{aligned}
$$

Because the temperature of the carbon dioxide changed from the inlet to the outlet and from the tube center to the wall, the transport properties also changed throughout the flow. We calculated $R e$ and $\operatorname{Pr}$ at the inlet, outlet, and at an average temperature (one half of the inlet plus outlet). The thermal conductivity used in $N u$ was evaluated at this average temperature. The density and 
specific heat were calculated from Span and Wagner (1996), while the viscosity and thermal conductivity were calculated using the functions of Vesovic et al. (1990). The functions of Vesovic et al. include the enhancement of both the thermal conductivity and the viscosity around the critical point.

\subsection{Experimental uncertainty}

A summary of the combined standard uncertainties are listed in Table 2. Uncertainties in the carbon dioxide property functions and equation of state were taken as $\pm 4 \%$ at the $95 \%$ confidence interval, based on Vesovic et al. (1990) and Span and Wagner (1996). Combined standard uncertainties in the calculated quantities (often referred to as standard deviation), such as $Q, U, h_{\mathrm{CO}_{2}}, \mathrm{Nu}, \mathrm{Re}$, and $\operatorname{Pr}$ were calculated using the "law of propagation of uncertainty" as stated in Taylor and Kuyatt (1994). This method involves writing a Taylor series approximation of those quantities and applying the partial derivatives of the quantity with respect to each variable times the standard uncertainty of the variable. Derivatives of the thermodynamic and transport properties were approximated with finite differences.

Multiplying the values in the Table by a coverage factor of 2 gives a $95 \%$ confidence interval that the actual uncertainty is less than or equal to the stated uncertainty. The Table also lists the largest sources of uncertainty for each calculated parameter. We can evaluate the quality of the measurements by comparing the combined standard uncertainty of the heat balance error $\left(Q_{\mathrm{H}_{2}}{ }^{-}\right.$ $\left.Q_{\mathrm{CO} 2}\right) / Q_{\mathrm{CO} 2}$ to the experimental standard deviation of the heat balance error. The experimental standard deviation of the error was $0.9 \%$, with a range of errors of $-1.5 \%$ to $+3.9 \%$. Twice the calculated standard uncertainty was $4.1 \%$ to $5.2 \%$, so the experimental errors were at worst no greater than the combined standard uncertainties, and were likely less. The largest source of uncertainty in $h_{\mathrm{CO}_{2}}$ was the uncertainty in $h_{\mathrm{H} 2 \mathrm{O}}$ (which could be as high as $10.6 \%$ ); the uncertainty in $h_{\mathrm{CO}_{2}}$ was largest when the magnitude of $h_{\mathrm{CO}_{2}}$ was high. Uncertainties in $h_{\mathrm{CO}_{2}}$ were always less than uncertainties in $h_{H 2 O}$ because the water heat transfer coefficient was much greater than the carbon dioxide heat transfer coefficient. The combined standard uncertainty in $\mathrm{Nu}$ ranged from $2.3 \%$ to $6.7 \%$, and was affected by both the uncertainties in $h_{\mathrm{CO} 2}$ and the thermal conductivity of the carbon dioxide.

\section{Results of experiments}

\subsection{Effects of experimental parameters on heat transfer coefficient}

Heat transfer coefficient for the supercritical carbon dioxide is plotted in Figs. 5 to 8 . These figures show representative data points from the experimental settings, rather than an average of

the multiple scans at each setting. Each of these figures present $h_{\mathrm{CO}_{2}}$ with respect to mass flux for different pressures, with heat flux held approximately constant. The pressure is expressed as a pressure ratio $P / P_{c}$, with $P_{c}$ the critical pressure. The successive figures are for increasing values of heat fluxes. Two trends can be seen on Fig. 5, the lowest heat flux tested. First, the heat transfer coefficient increased as the mass flux increased for all pressures. This trend would be 
the same for a constant property (non-supercritical) fluid. Second, as the pressure increased, $h_{\mathrm{CO} 2}$ decreased for all values of the mass flux. At this low heat flux, the heat transfer coefficient was highest at the lowest pressure (close to the critical) and at high mass flux, which also corresponds to high Reynolds number.

Examining Figs. 6 to 8 for other values of the heat flux shows that an increase in mass flux always increased $h_{\mathrm{CO}_{2}}$. At high mass flux, decreasing the pressure still increased $h_{\mathrm{CO}_{2}}$. However, at low mass flux, the data appeared to collapse to a single curve in which pressure did not change the heat transfer coefficient. The range of values of mass flux over which pressure did not affect $h_{\mathrm{CO} 2}$ increased as the heat flux increased.

Figures 9 to 10 show the effect of heat flux on $h_{\mathrm{CO}_{2}}$ for constant pressure. In Fig. 9 we plot $h_{\mathrm{CO}_{2}}$ vs mass flux for $P / P_{c}=1.05$ at four values of heat flux. We again see that increasing the mass flux increased $h_{\mathrm{CO}_{2}}$. Increasing the heat flux decreased $h_{\mathrm{CO}_{2}}$ except when the mass flux (Reynolds number) was high. There appeared to be an optimal value in the heat flux, at about $30 \mathrm{~kW} / \mathrm{m}^{2}$, which maximized $h_{\mathrm{CO}_{2}}$ when the mass flux was high. Figure 10 shows the data at a higher pressure, $P / P_{c}=1.77$. At the high pressure, an increase in heat flux produced only a slight decrease in $h_{\mathrm{CO}_{2}}$. Carbon dioxide at this pressure behaved more like a constant property fluid, in which heat flux would have no effect on the heat transfer coefficient.

\subsection{Comparisons of the data with constant property predictions}

In Figs. 11 and 12, we replot $h_{\mathrm{CO}_{2}}$ for the lowest and highest pressure and the lowest and highest heat fluxes from Figs. 5 to 8, and add the predicted heat transfer coefficient for a constant property fluid (evaluated at the temperature and pressure of the experimental setting). For the predicted constant property value, we use the Petukhov correlation as modified by Gnielinski (1976). This is believed to be the most accurate representation for heat transfer in a tube, with a stated accuracy of $10 \%$ over $2300<\operatorname{Re}<5 \times 10^{6}$ and $0.5<\operatorname{Pr}<2000$ (Rohsenow et al, 1985):

$$
N u_{P G}=\frac{\frac{f}{2}(R e-1000) \operatorname{Pr}}{1+12.7\left(\frac{f}{2}\right)^{1 / 2}\left(\operatorname{Pr}^{2 / 3}-1\right)}\left[1+\left(\frac{D}{L}\right)^{2 / 3}\right] .
$$

The term in the brackets accounts for entry length effects; the friction factor, $f$, is given by the Kármán-Nikuradse correlation:

$$
\frac{1}{\sqrt{f}}=4.0 \log _{10}(R e \cdot \sqrt{f})-0.4
$$

The predicted $h_{P G}$ equals $N u_{P G} k D$. The fluid properties, $R e$, and $\operatorname{Pr}$ were evaluated at the average 
carbon dioxide temperature for the correlation. In Fig. 11 for the low heat flux, we see that the Petukhov-Gnielinski correlation predicted the heat transfer coefficient well at the high pressure (maximum deviation of $3.2 \%$ ), but underpredicted the heat transfer for all flow rates at the low pressure. That is; at the low heat flux and low pressure there was an enhancement (defined as (measured-predicted)/predicted) in the heat transfer process that significantly exceeded that due to the more favorable transport properties alone. This enhancement was as high as $32 \%$. The constant property correlation predicted a higher heat transfer coefficient as the pressure was decreased, due to the increased thermal conductivity and specific heat at the lower pressures, but not as much as was measured. At high pressure and low heat flux, the fluid can still be treated as a constant property fluid for predicting the heat transfer.

In Fig. 12 for the high heat flux, the Petukhov-Gnielinski correlation again predicted higher $h_{C O}$ as the pressure was reduced; this effect is independent of heat flux. Now, though, the measured $h_{\mathrm{CO}_{2}}$ was lower than the predicted values for both pressures, by as much as $47 \%$ at the low pressure and $20 \%$ at the high pressure. At high heat flux there was a degradation in the heat transfer process that could not be predicted by the constant property correlation. This degradation lessened as the mass flux increased and the pressure increased, and was only $3 \%$ above $750 \mathrm{~kg} /\left(\mathrm{m}^{2} \mathrm{~s}\right)$ mass flux and at high pressure. For intermediate values of heat flux, between those shown in Figs. 11 to 12, there were regions of enhancement at high mass flux and degradation at low mass flux.

\subsection{Comparisons of the data with supercritical correlations}

Measurements made in past investigations for supercritical flows undergoing heating, with a constant heat flux boundary condition, also exhibited heat transfer enhancement at low heat fluxes and heat transfer degradation at high heat flux. Several investigators have developed heat transfer correlations which are modifications to the constant property correlation. They try to include terms in their correlations which follow the heat flux trends. Jackson and Hall (1978) extensively reviewed the correlations in the literature and recommended the following correlation as the "best" for turbulent flow in both water and carbon dioxide, which is from Krashnoschekov and Protopopov (1966). They defined "best" as the largest percentage agreement between measured and predicted Nusselt numbers at the available data points; for this correlation, $84 \%$ of the available data in 1978 agreed to within $\pm 15 \%$ of the correlation, and $93 \%$ of the data agreed to within $\pm 20 \%$ of the correlation. This correlation modified the Petukhov-Gnielinski correlation by a density ratio and a specific heat ratio:

$$
N u_{K P}=N u_{P G}\left(\frac{\rho_{w}}{\rho_{b}}\right)^{0.3}\left(\frac{\bar{c}_{p}}{c_{p, b}}\right)^{n},
$$

where 


$$
\bar{c}_{p}=\frac{i_{w}-i_{b}}{T_{w}-T_{b}}
$$

The subscript " $w$ " signifies the variable is evaluated at the conditions of the wall; the subscript " $b$ " signifies an evaluation at the bulk flow conditions of the $\mathrm{CO}_{2}$. For our data, we used the average flow temperature for the bulk temperature. The wall temperature was calculated by writing a local heat balance at the bulk temperature conditions:

$$
\left(T_{H_{2} \mathrm{O}}-T_{W}\right) \frac{1}{\frac{r_{i}}{k_{s s}} \ln \frac{r_{o}}{r_{i}}+\frac{r_{i}}{r_{o}} \frac{1}{h_{H_{2} O} \mathrm{O}}}=\left(T_{\mathrm{H}_{2} \mathrm{O}}-T_{b}\right) U .
$$

The exponent $n$ in Eq. 11 depends on the wall temperature, bulk temperature, and the temperature for which $c_{p}$ is maximum at the operating pressure $\left(T_{m}\right)$ :

$$
\begin{array}{ll}
\text { if } T_{w} / T_{m}<1.0 \text { or if } T_{b} / T_{m} \geq 1.2: & n=0.4 \\
\text { if } T_{b} / T_{m}<1.0 \leq T_{w} / T_{m}: & n=0.4+0.18\left(\frac{T_{w}}{T_{m}}-1\right) \\
\text { if } T_{w} / T_{m} \geq 1.0 \text { and } 1.0<T_{b} / T_{m}<1.2: & n=0.4+0.18\left(\frac{T_{w}}{T_{m}}-1\right)\left[1-5\left(\frac{T_{b}}{T_{m}}-1\right)\right] .
\end{array}
$$

For our data, $n$ almost always equaled 0.4 . The wall temperature was always higher than the bulk temperature, so the density ratio was less than one. As the heat flux increased, the density ratio decreased; this term qualitatively approximates the effect of increased degradation at high heat flux. When the peak in specific heat (Fig. 1) occurred between the wall and bulk temperatures, the specific heat ratio was greater than one. For low heat flux, the increase in the specific heat ratio was larger than the decrease in the density ratio, which approximates the enhancement in the heat transfer.

In Fig. 13 we have plotted representative points for all the experimental settings of the six data sets, as $N u_{K P}$ versus the measured Nusselt number, $N u_{\text {meas }}$. Also plotted are a $45^{\circ}$ line representing exact agreement to the experimental data and $\pm 7 \%$ deviation lines. The calculated combined standard uncertainty at the $95 \%$ confidence interval ranged from $4.8 \%$ to $13.4 \%$, with the largest relative uncertainty at the highest $N u$. The $N u_{K P}$ correlation, which was developed for constant heat flux boundary conditions, also predicts our data very well, which had a convective boundary condition. The Reynolds number range was 34300 to 154600 . Statistics on the comparison of $N u_{\text {meas }}$ to both correlation equations $\left(N u_{P G}\right.$ and $\left.N u_{K P}\right)$ are given in Table 3. (These are comparisons of the data to the correlations, not calculations of standard uncertainties). Recall that for data sets 1 and 5 we did not vary the flow rate and heat rate over the full range. The fit of the constant property correlation, $N u_{P G}$, was always worse than the fit of 
the supercritical correlation, $N u_{K P}$. The constant property fit became better as the pressure increased; at $13.1 \mathrm{MPa}$, the standard deviation was $6.6 \%$, compared to the combined standard uncertainty ( $95 \%$ confidence interval) of $4.8 \%$ to $9.0 \%$. However, even at this pressure, the deviation at low flow rate and high heating was $-19.6 \%$. The standard deviation of all $N u_{\text {meas }}$ to $N u_{K P}$ was $3.0 \%$, with an average difference of $1.0 \%$. The range of the difference was $-9.6 \%$ to $10.1 \%$.

\subsection{Summary and conclusions}

In this work we have measured the heat transfer coefficient in turbulent, supercritical carbon dioxide flowing in a horizontal tube. The carbon dioxide was heated by water flowing countercurrent in the annular gap outside the tube containing the carbon dioxide. This convective boundary condition is the same as in a heat exchanger in which the supercritical carbon dioxide exchanges heat with another fluid, such as the "gas cooler" in a refrigeration cycle. The direction of the heat flow, however, is opposite (heating vs cooling). All past measurement of heat transfer in supercritical fluids have been with either constant heating at the walls or constant wall temperature.

Our measurements showed that the heat transfer coefficient always increased with increasing flow rate. At low heat flux, the heat transfer coefficient increased as the pressure decreased. At high heat flux, the heat transfer coefficient was nearly independent of pressure at low flow rate, while at high flow rate it still increased as the pressure decreased. At any given pressure, low heat flux generally produced the highest heat transfer coefficient, although when the flow rate was high there appeared to be an optimum heat flux of about $30 \mathrm{~kW} / \mathrm{m}^{2}$. By comparing the measurements to the values expected if the fluid had constant properties, we find that the supercritical fluid had enhanced heat transfer at low heat flux and degraded heat transfer at high heat flux. This enhancement and degradation was more pronounced as the pressure decreased toward the critical. The Krashnoschekov-Protopopov correlation, developed for supercritical turbulent flow with a constant heat flux boundary condition, fit the measured data to within a standard deviation of $3.0 \%$.

The Krashnoschekov-Protopopov correlation can be used for heated turbulent flow to predict the heat transfer over the range of the parameters tested in the present work. It can also be extrapolated beyond the range of parameters to higher pressure, higher mass rate, and lower heat flux, since these are conditions where the errors in the fit decreased. It should not be extrapolated to lower pressure, lower mass flux, or higher heat flux than those tested in this work.

\section{Acknowledgments}

The authors greatly acknowledge the assistance of the Statistical Engineering Division of NIST in evaluating experimental uncertainties and in experimental design. The Thermal Machinery Group of NIST provided valuable advice throughout the project. 
Gallagher, J.S., and Haar, L., 1988, "NIST Standard Reference Database 10: NIST Thermodynamic Properties of Water (STEAM)," U.S. Department of Commerce, NIST.

Gnielinski, V., 1976, "New equations for heat and mass transfer in turbulent pipe and channel flow," International Chemical Engineering, Vol. 16, no.2, pp. 359-368.

Hall, W.B., and Jackson, J.D., 1978, "Heat transfer near the critical point," Proceedings of the $6^{\text {th }}$ International Heat Transfer Conference, Vol. 6., pp. 377-392.

Jackson, J.D., and Hall, W.B., 1978, "Forced convection heat transfer to fluids at supercritical pressure," in Turbulent Forced Convection in Channels and Bundles, Vol. 2, pp. 563-611, NATO Advanced Study Institute.

Krashnoschekov, E.A., and Protopopov, V.S., 1966, "Experimental study of heat exchange in carbon dioxide in the supercritical range at high temperature drops," Teplofizika Vyosokikh Temperatur, Vol. 4, no.3, pp. 389-398.

Lorentzen, G., and Pettersen, J., 1993, "A new, efficient and environmentally benign system for car air-conditioning," International Journal of Refrigeration, Vol. 16, no. 1, pp. 4-12.

Manzione, J.A., 1998, "Development of carbon dioxide environmental control unit for the US Army", Proceedings of the International Institute of Refrigeration Sections B and E, pp. 251256, Oslo, Norway.

Rohsenow, W.M., and Choi, H., 1961, Heat, Mass, and Momentum Transfer, Prentice-Hall, Inc..

Rohsenow, W.M., Hartnett, J.P., and Ganić, E.N., 1985, Handbook of Heat Transfer Applications, McGraw-Hill, Inc.

Span, R., and Wagner, W., 1996, "A new equation of state for $\mathrm{CO}_{2}$ covering the fluid region from the triple point temperature to $1100 \mathrm{~K}$ at pressures up to $800 \mathrm{MPa}$," Journal of Physical and Chemical Reference Data, Vol. 25, no. 6, pp. 1509-1596.

Taylor, B.N., and Kuyatt, C.E., 1994, "Guidelines for evaluating and expressing the uncertainty of NIST measurement results," NIST Technical Note 1297: 1994 Edition.

Vesovic, V., Wakeham, W.A., Olchowy, G.A., Senger., J.V., Watson, J.T.R., and Millat, J., 1990, "The transport properties of carbon dioxide," Journal of Physical and Chemical Reference Data," Vol. 19, no. 3, pp. 763-808.

Walisch, T., Dörfler, W., and Trepp, Ch., 1997, "Heat transfer to supercritical carbon dioxide in 
tubes with mixed convection," Proceedings of the $32^{\text {nd }}$ National Heat Transfer Conference, Vol. 12, pp. 79-98. 
Table 1. Summary of test section parameters and experimental conditions.

Inner tube inner diameter: $10.922 \mathrm{~mm}$ Inner tube outer diameter: $12.799 \mathrm{~mm}$ Outer tube inner diameter: $16.561 \mathrm{~mm}$

Outer tube outer diameter: $19.050 \mathrm{~mm}$

Carbon dioxide tube hydraulic diameter: $10.922 \mathrm{~mm}$

Water annulus hydraulic diameter: $3.8608 \mathrm{~mm}$

Heated tube length: $2.743 \mathrm{~m}$

Carbon dioxide flow area: $9.369 \times 10^{-5} \mathrm{~m}^{2}$

Water flow area: $8.873 \times 10^{-5} \mathrm{~m}^{2}$

Heat transfer area: $9.413 \times 10^{-2} \mathrm{~m}^{2}$

\begin{tabular}{|c|c|c|c|c|c|c|c|}
\hline $\begin{array}{c}\text { Expt. } \\
\text { Set }\end{array}$ & Date & $\begin{array}{c}\text { No. } \\
\text { Settings }\end{array}$ & $\begin{array}{c}\text { No. } \\
\text { Data } \\
\text { Points }\end{array}$ & $\begin{array}{c}\mathrm{CO}_{2} \\
\text { Pressure } \\
(\mathrm{MPa})\end{array}$ & $\begin{array}{c}\mathrm{CO}_{2} \text { Flow } \\
\text { Rate } \\
(\mathrm{kg} / \mathrm{min})\end{array}$ & $\begin{array}{c}\text { Heating } \\
\text { (W) }\end{array}$ & $\begin{array}{c}\mathrm{CO}_{2} \text { Inlet } \\
\text { Temperature } \\
\left({ }^{\circ} \mathrm{C}\right)\end{array}$ \\
\hline 1 & 12 Dec. 1997 & 13 & 98 & 8.6 & 1.6 to 2.9 & 1150 to 4750 & 3.6 to 13.5 \\
\hline 2 & 2 June 1998 & 22 & 244 & $8.4,8.6$ & 1.1 to 4.7 & 1870 to 5920 & -0.1 to 27.3 \\
\hline 3 & 4 June 1998 & 21 & 233 & 10.4 & 1.2 to 4.8 & 2010 to 6180 & -0.7 to 30.3 \\
\hline 4 & 22 June 1998 & 21 & 231 & 13.1 & 1.4 to 5.1 & 1910 to 6170 & 0.9 to 32.7 \\
\hline 5 & 24 June 1998 & 7 & 77 & 9.4 & 1.2 to 4.6 & 2910 to 4560 & 10.0 to 28.3 \\
\hline 6 & 25 June 1998 & 21 & 232 & 7.78 to 7.9 & 1.0 to 4.5 & 1840 to 5860 & -1.7 to 25.8 \\
\hline
\end{tabular}

\begin{tabular}{|c|c|c|c|c|c|}
\hline Expt. Set & $\begin{array}{c}\mathrm{CO}_{2} \text { Average } \\
\text { Temperature } \\
\left({ }^{\circ} \mathrm{C}\right)\end{array}$ & $\begin{array}{c}\mathrm{CO}_{2} \text { Reynolds } \\
\text { Number }\end{array}$ & $\begin{array}{c}\text { Log Mean } \\
\text { Temp. Diff. } \\
\left({ }^{\circ} \mathrm{C}\right)\end{array}$ & $\begin{array}{c}\mathrm{CO}_{2} \text { Heat Transfer } \\
\text { Coefficient } \\
\left(\mathrm{W} /\left(\mathrm{m}^{2} \mathrm{~K}\right)\right)\end{array}$ & $\begin{array}{c}\mathrm{CO}_{2} \text { Nusselt } \\
\text { Number }\end{array}$ \\
\hline 1 & 16.9 to 26.4 & 37875 to 68540 & 10.5 to 41.5 & 1509 to 2554 & 172 to 290 \\
\hline 2 & 28.6 to 31.4 & 37235 to 151125 & 7.5 to 64.8 & 853 to 4961 & 115 to 659 \\
\hline 3 & 33.0 to 34.3 & 39020 to 153235 & 8.2 to 60.6 & 991 to 4361 & 132 to 578 \\
\hline 4 & 35.1 to 38.4 & 40455 to 147200 & 8.4 to 57.0 & 1057 to 3972 & 136 to 503 \\
\hline 5 & 31.2 to 33.6 & 41070 to 154600 & 11.5 to 50.8 & 988 to 4813 & 135 to 649 \\
\hline 6 & 28.0 to 30.4 & 34310 to 150525 & 7.3 to 65.5 & 787 to 6230 & 107 to 831 \\
\hline
\end{tabular}


Table 2. Summary of standard uncertainties for measured parameters and combined standard uncertainties for calculated parameters.

\begin{tabular}{|c|c|c|}
\hline Parameter & Major Source of Uncertainty & Magnitude of uncertainty \\
\hline $\mathrm{CO}_{2}$ mass flow rate & Instrument calibration & $0.075 \%+0.34 \mathrm{~kg} / \mathrm{h}$ \\
\hline Water mass flow rate & Instrument calibration & $0.05 \%+0.082 \mathrm{~kg} / \mathrm{h}$ \\
\hline Fluid temperature & Instrument calibration & $0.025^{\circ} \mathrm{C}$ \\
\hline $\mathrm{CO}_{2}$ absolute pressure & Instrument calibration & $2070 \mathrm{~Pa}$ \\
\hline $\mathrm{CO}_{2}$ differential pressure & Instrument calibration & $43 \mathrm{~Pa}$ \\
\hline Water absolute pressure & Instrument calibration & $2600 \mathrm{~Pa}$ \\
\hline Water differential pressure & Instrument calibration & $430 \mathrm{~Pa}$ \\
\hline $\begin{array}{l}\mathrm{CO}_{2} \text { specific enthalpy and } \\
\text { specific heat }\end{array}$ & Equation of state & $2 \%$ \\
\hline $\begin{array}{l}\mathrm{CO}_{2} \text { viscosity and thermal } \\
\text { conductivity }\end{array}$ & Function accuracy & $2 \%$ \\
\hline Heat balance error & $\mathrm{CO}_{2}$ specific enthalpy function & $2.0 \%$ to $3.3 \%$ \\
\hline Water heat transfer coefficient & $\begin{array}{l}\text { Curve fit to NIST calibration } \\
\text { data }\end{array}$ & $9.5 \%$ to $10.6 \%$ \\
\hline $\mathrm{CO}_{2}$ heat transfer coefficient & Water heat transfer coefficient & $1.3 \%$ to $6.4 \%$ \\
\hline $\mathrm{CO}_{2}$ Nusselt number & $\begin{array}{l}\mathrm{CO}_{2} \text { heat transfer coefficient, } \\
\text { thermal conductivity }\end{array}$ & $2.3 \%$ to $6.7 \%$ \\
\hline $\mathrm{CO}_{2}$ Reynolds number & $\mathrm{CO}_{2}$ viscosity & $2.0 \%$ to $2.1 \%$ \\
\hline $\mathrm{CO}_{2}$ Prandtl number & $\begin{array}{l}\mathrm{CO}_{2} \text { viscosity, specific heat, } \\
\text { thermal conductivity }\end{array}$ & $3.5 \%$ \\
\hline
\end{tabular}

Multiplying the Table values by a coverage factor of 2 will yield a $95 \%$ confidence interval. 
Table 3. Comparison of measured Nusselt number to values predicted by Petukhov-Gnielinski (constant property) correlation and to Krashnochekov-Protopopov (supercritical, constant heat flux) correlation.

\begin{tabular}{|c|c|c|c|c|c|c|c|}
\hline \multirow{2}{*}{$\begin{array}{c}\text { Expt. } \\
\text { Set }\end{array}$} & \multirow{2}{*}{$\begin{array}{c}\text { Pressure } \\
(\mathrm{MPa})\end{array}$} & \multicolumn{3}{|c|}{$\begin{array}{c}\text { Constant Property } \\
\text { Petukhov-Gnielinski } \\
\mathrm{Nu}_{\text {meas }} \mathrm{Nu}_{\mathrm{pg}}-1\end{array}$} & \multicolumn{3}{c|}{$\begin{array}{c}\text { Supercritical, Constant Heat Flux } \\
\text { Krashnochekov-Protopopov } \\
\text { Nu }_{\text {meas }} \text { Nu }_{\mathrm{kp}}-1\end{array}$} \\
\cline { 3 - 8 } & & $\begin{array}{c}\text { Standard } \\
\text { Deviation }\end{array}$ & $\begin{array}{c}\text { Maximum } \\
\text { Positive }\end{array}$ & $\begin{array}{c}\text { Maximum } \\
\text { Negative }\end{array}$ & $\begin{array}{c}\text { Standard } \\
\text { Deviation }\end{array}$ & $\begin{array}{c}\text { Maximum } \\
\text { Positive }\end{array}$ & $\begin{array}{c}\text { Maximum } \\
\text { Negative }\end{array}$ \\
\hline 1 & 8.6 & $8.0 \%$ & $9.1 \%$ & $-14.1 \%$ & $2.0 \%$ & $2.4 \%$ & $-3.7 \%$ \\
\hline 2 & $8.4,8.6$ & $17.0 \%$ & $15.2 \%$ & $-38.8 \%$ & $2.8 \%$ & $7.4 \%$ & $-6.5 \%$ \\
\hline 3 & 10.4 & $10.5 \%$ & $4.8 \%$ & $-25.6 \%$ & $2.7 \%$ & $10.1 \%$ & $-4.3 \%$ \\
\hline 4 & 13.1 & $6.6 \%$ & $3.3 \%$ & $-19.6 \%$ & $1.6 \%$ & $3.6 \%$ & $-2.3 \%$ \\
\hline 5 & 9.4 & $15.1 \%$ & $9.5 \%$ & $-31.8 \%$ & $1.8 \%$ & $3.4 \%$ & $0.0 \%$ \\
\hline 6 & 7.78 to 7.9 & $26.1 \%$ & $32.0 \%$ & $-47.4 \%$ & $4.9 \%$ & $9.4 \%$ & $-6.0 \%$ \\
\hline all data & & $15.9 \%$ & $32.0 \%$ & $-47.4 \%$ & $3.0 \%$ & $10.1 \%$ & $-6.5 \%$ \\
\hline
\end{tabular}

For comparison, the combined standard uncertainty for the measured Nusselt number was $2.3 \%$ to $6.7 \%$. 


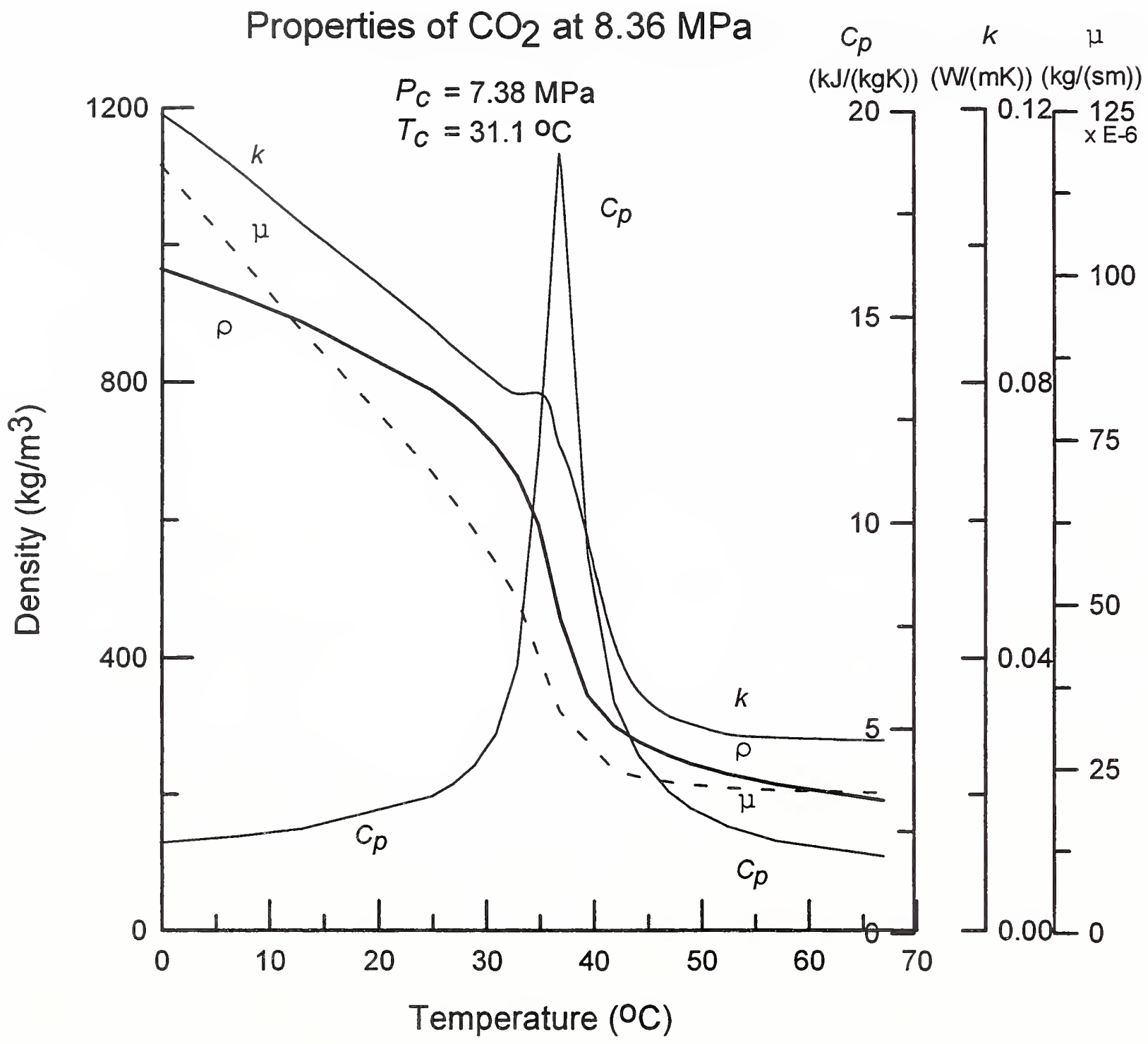

Figure 1. Properties of carbon dioxide on the $8.36 \mathrm{MPa}$ isobar from $0{ }^{\circ} \mathrm{C}$ to $70{ }^{\circ} \mathrm{C}$. 


\section{Carbon Dioxide Flow Loop}

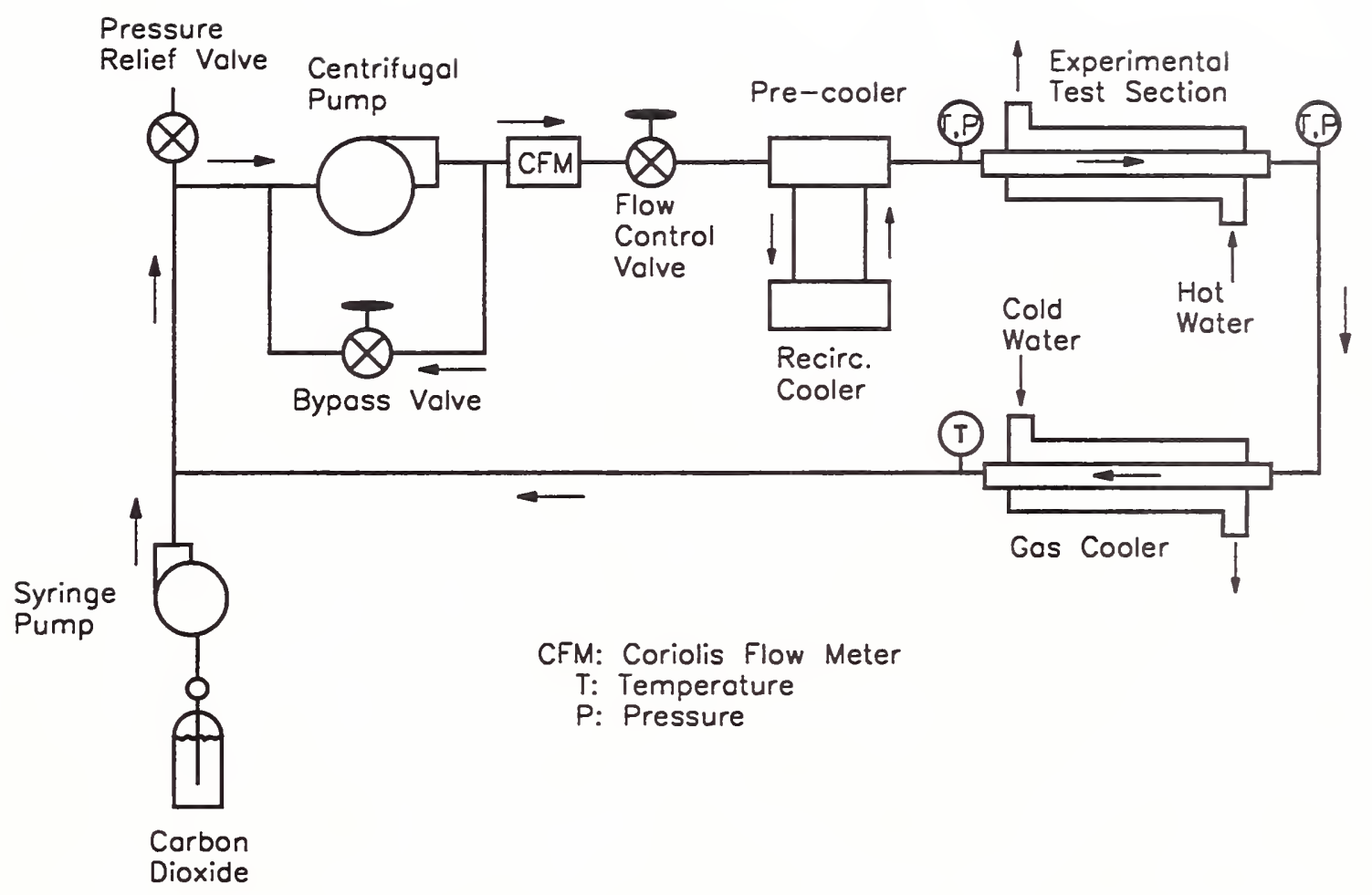

Figure 2. Carbon dioxide flow loop of the NIST supercritical heat transfer facility. 


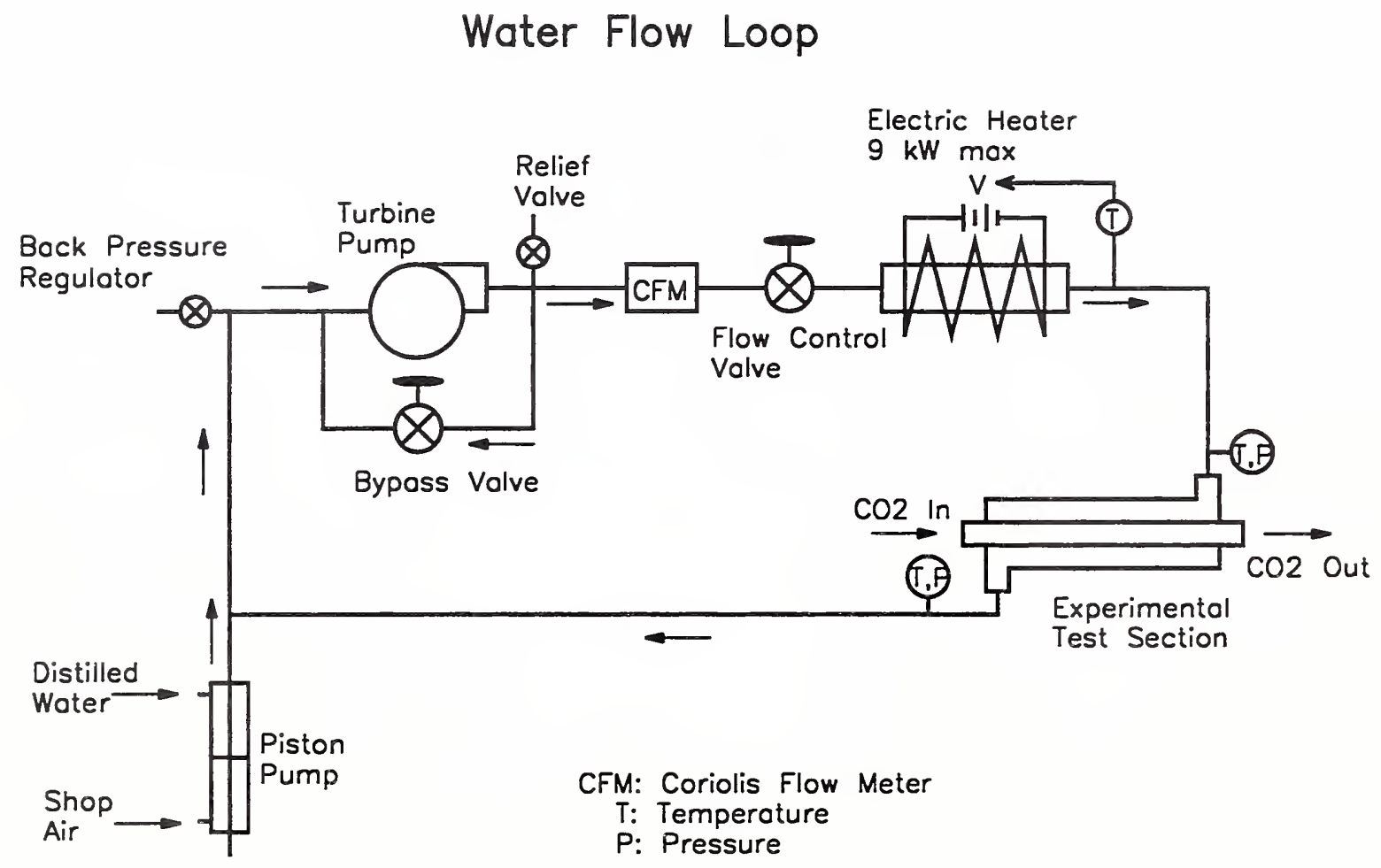

Figure 3. Water flow loop of the NIST supercritical heat transfer facility. 


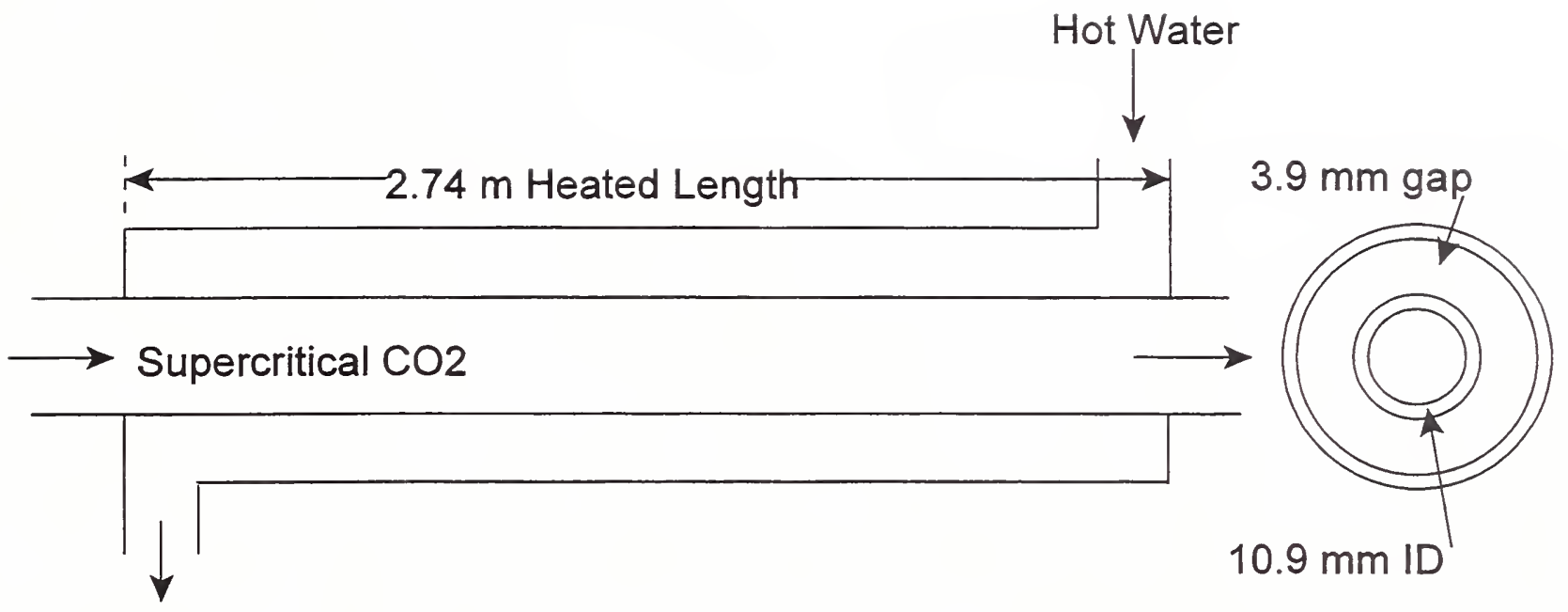

Figure 4. Counterflow heat exchanger test section. 


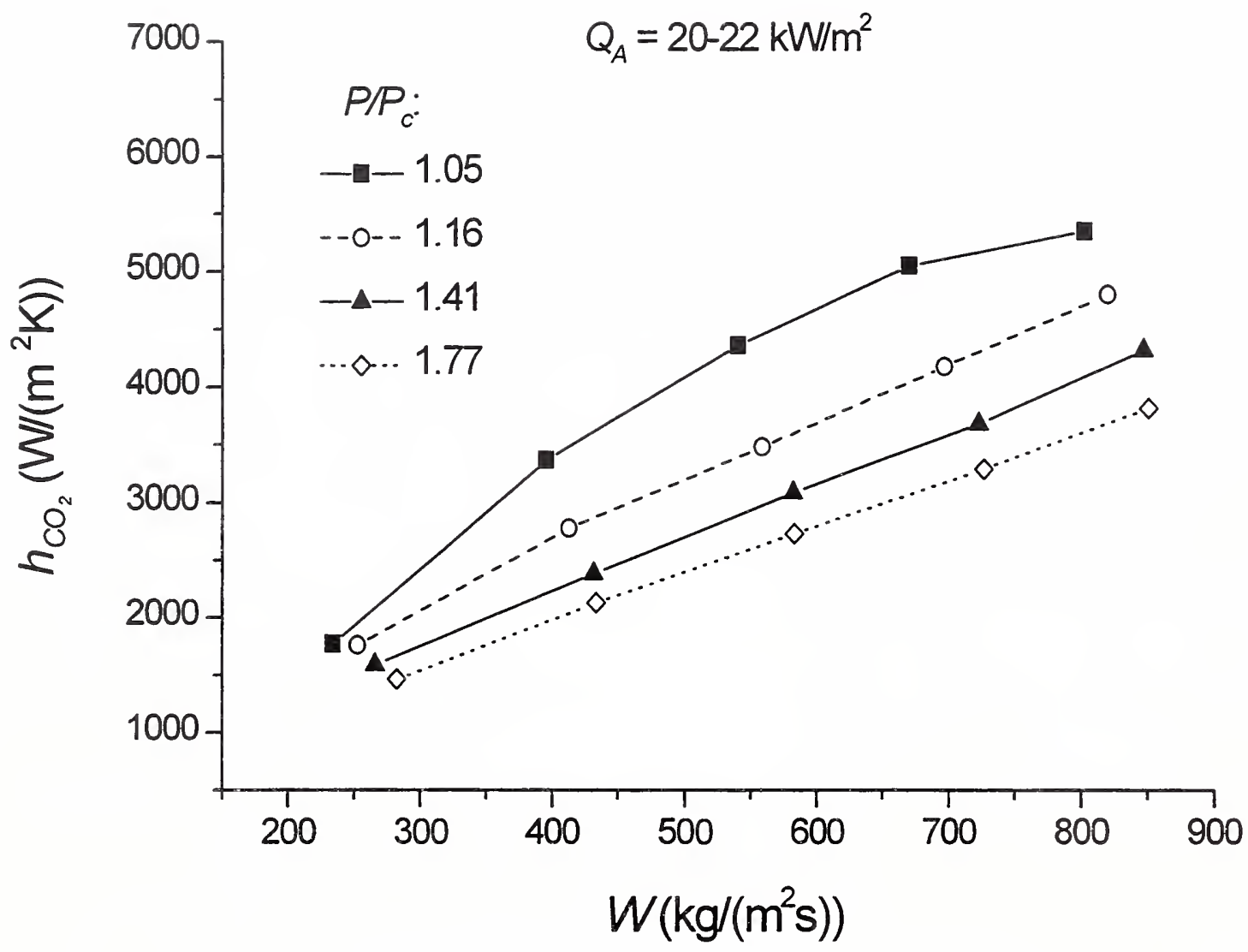

Figure 5. $\quad \mathrm{CO}_{2}$ heat transfer coefficient $(h)$ as a function of mass flux $(W)$ for several values of pressure $\left(P / P_{c}\right)$ at a heat flux $\left(Q_{A}\right)$ of $20 \mathrm{~kW} / \mathrm{m}^{2}$ to $22 \mathrm{~kW} / \mathrm{m}^{2}$. 


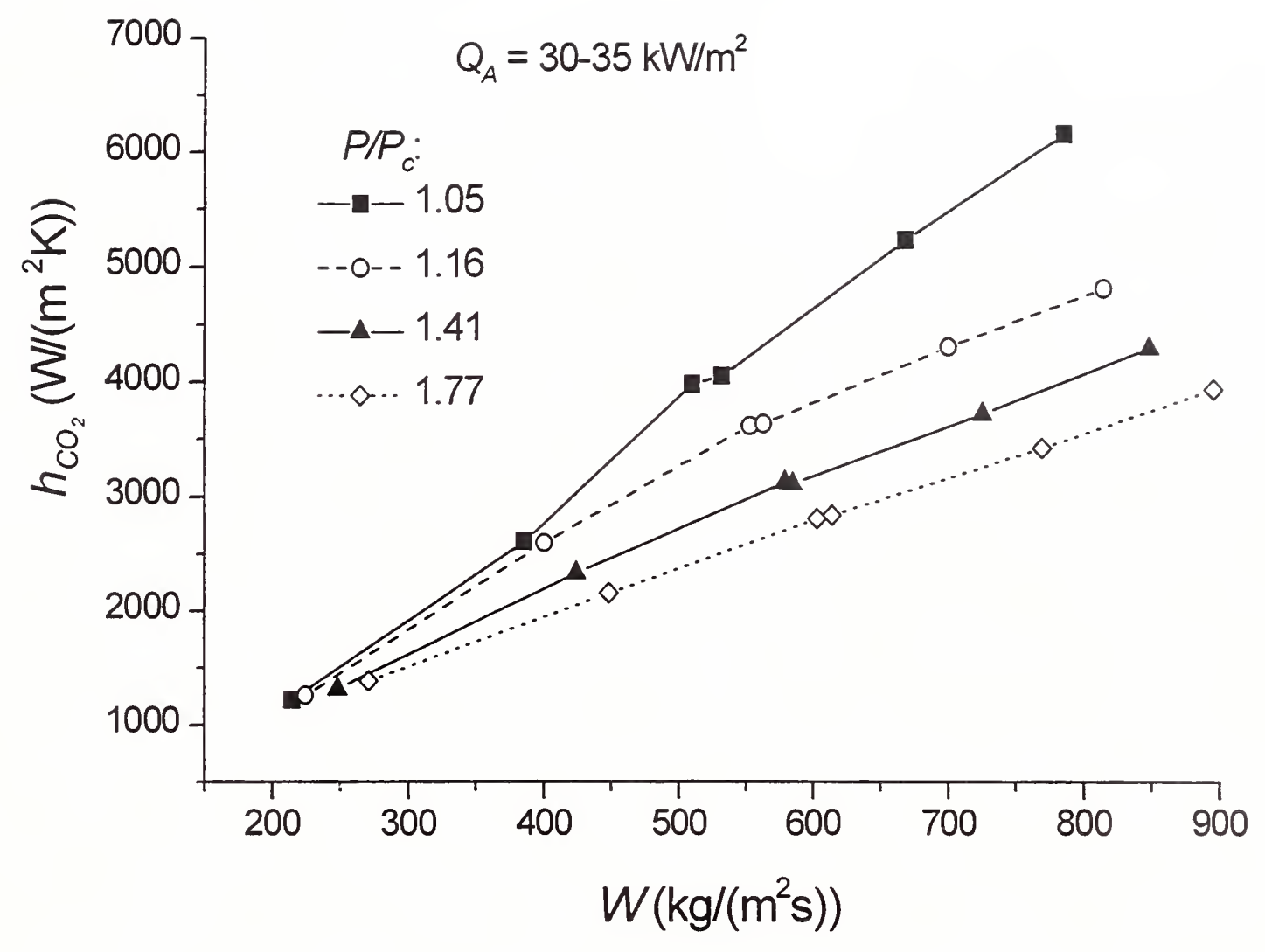

Figure 6. $\quad \mathrm{CO}_{2}$ heat transfer coefficient $(h)$ as a function of mass flux $(W)$ for several values of pressure $\left(P / P_{c}\right)$ at a heat flux $\left(Q_{A}\right)$ of $30 \mathrm{~kW} / \mathrm{m}^{2}$ to $35 \mathrm{~kW} / \mathrm{m}^{2}$. 


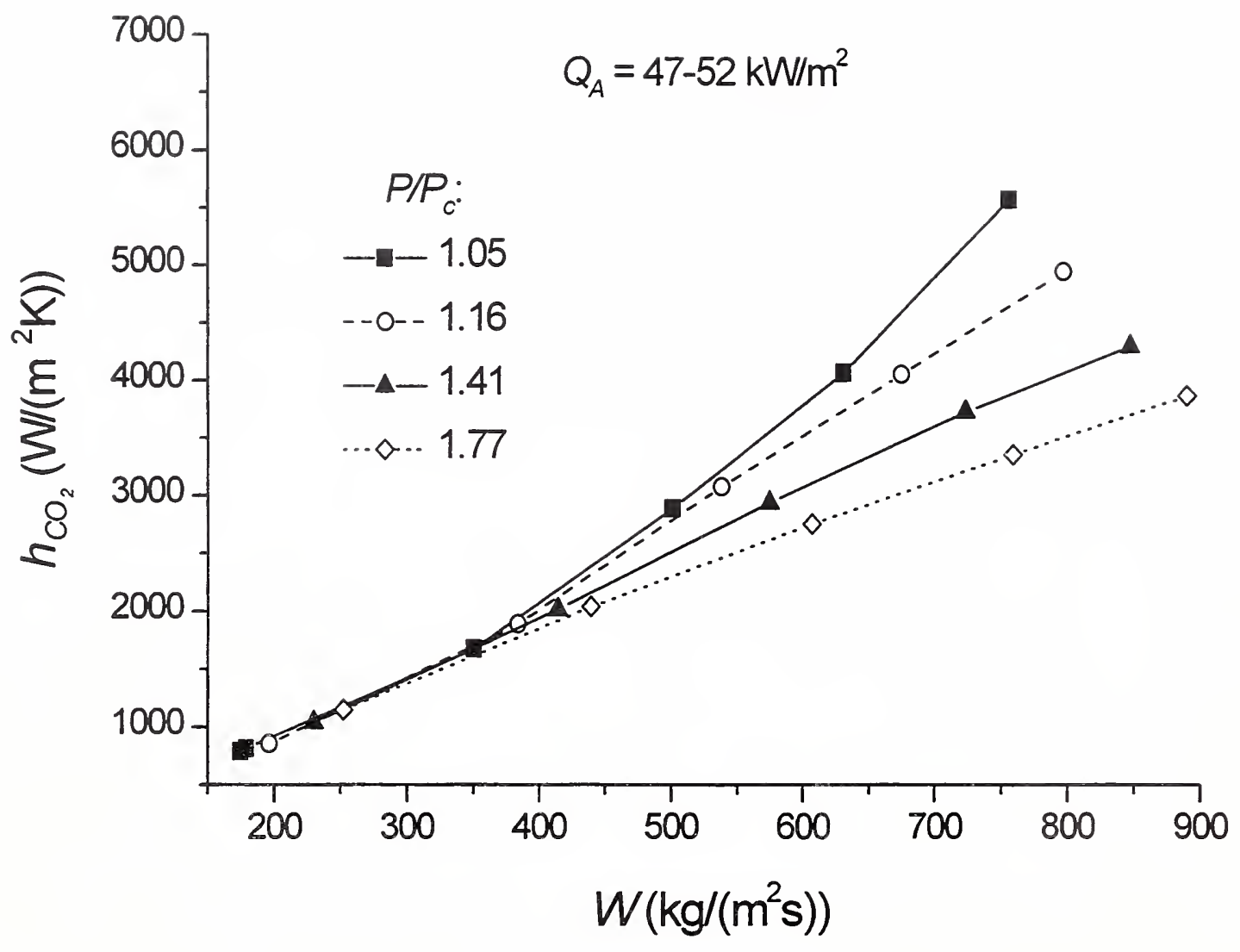

Figure 7. $\quad \mathrm{CO}_{2}$ heat transfer coefficient $(h)$ as a function of mass flux $(W)$ for several values of pressure $\left(P / P_{c}\right)$ at a heat flux $\left(Q_{A}\right)$ of $47 \mathrm{~kW} / \mathrm{m}^{2}$ to $52 \mathrm{~kW} / \mathrm{m}^{2}$. 


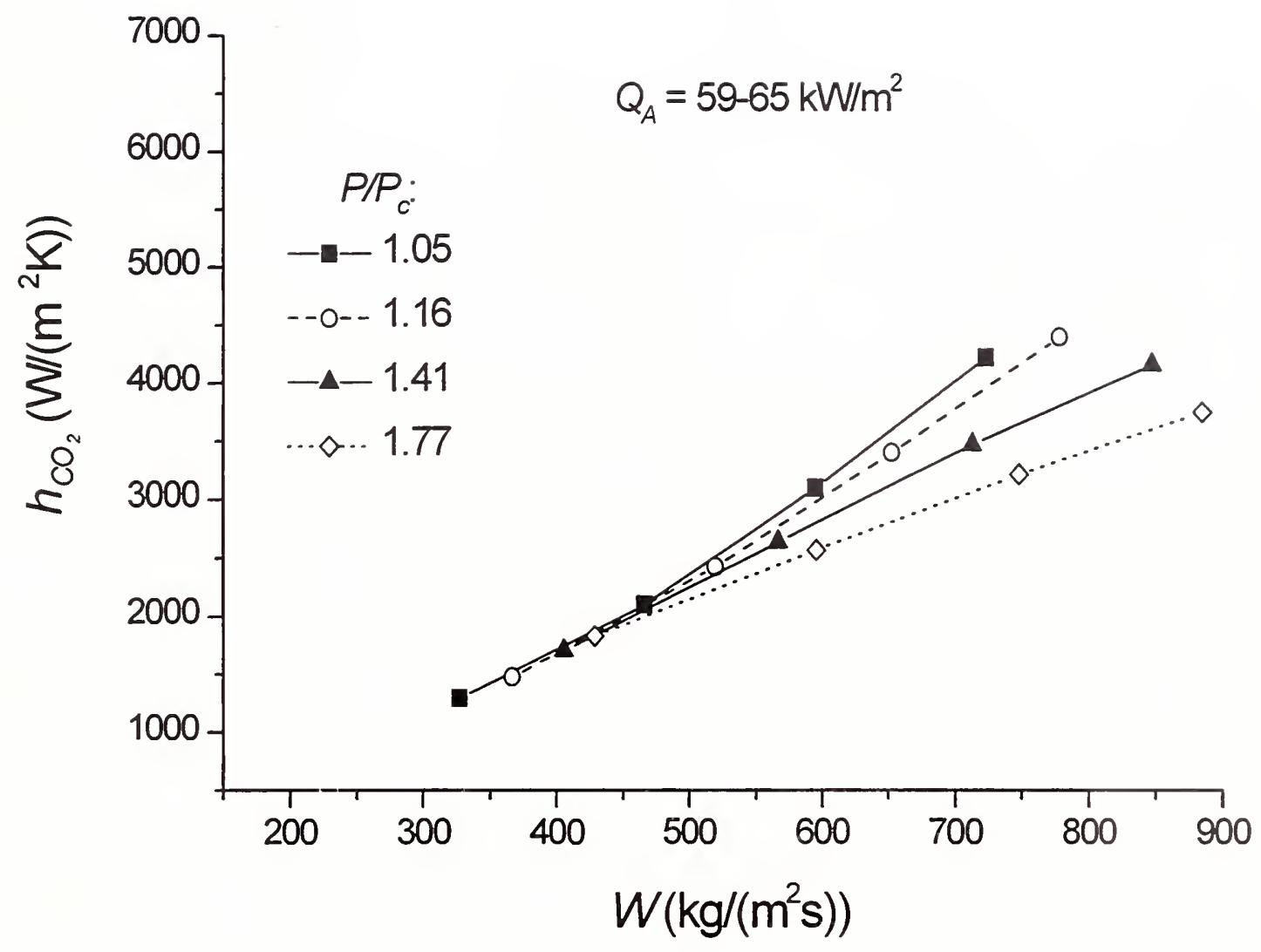

Figure 8. $\quad \mathrm{CO}_{2}$ heat transfer coefficient $(h)$ as a function of mass flux $(W)$ for several values of pressure $\left(P / P_{c}\right)$ at a heat flux $\left(Q_{A}\right)$ of $59 \mathrm{~kW} / \mathrm{m}^{2}$ to $65 \mathrm{~kW} / \mathrm{m}^{2}$. 


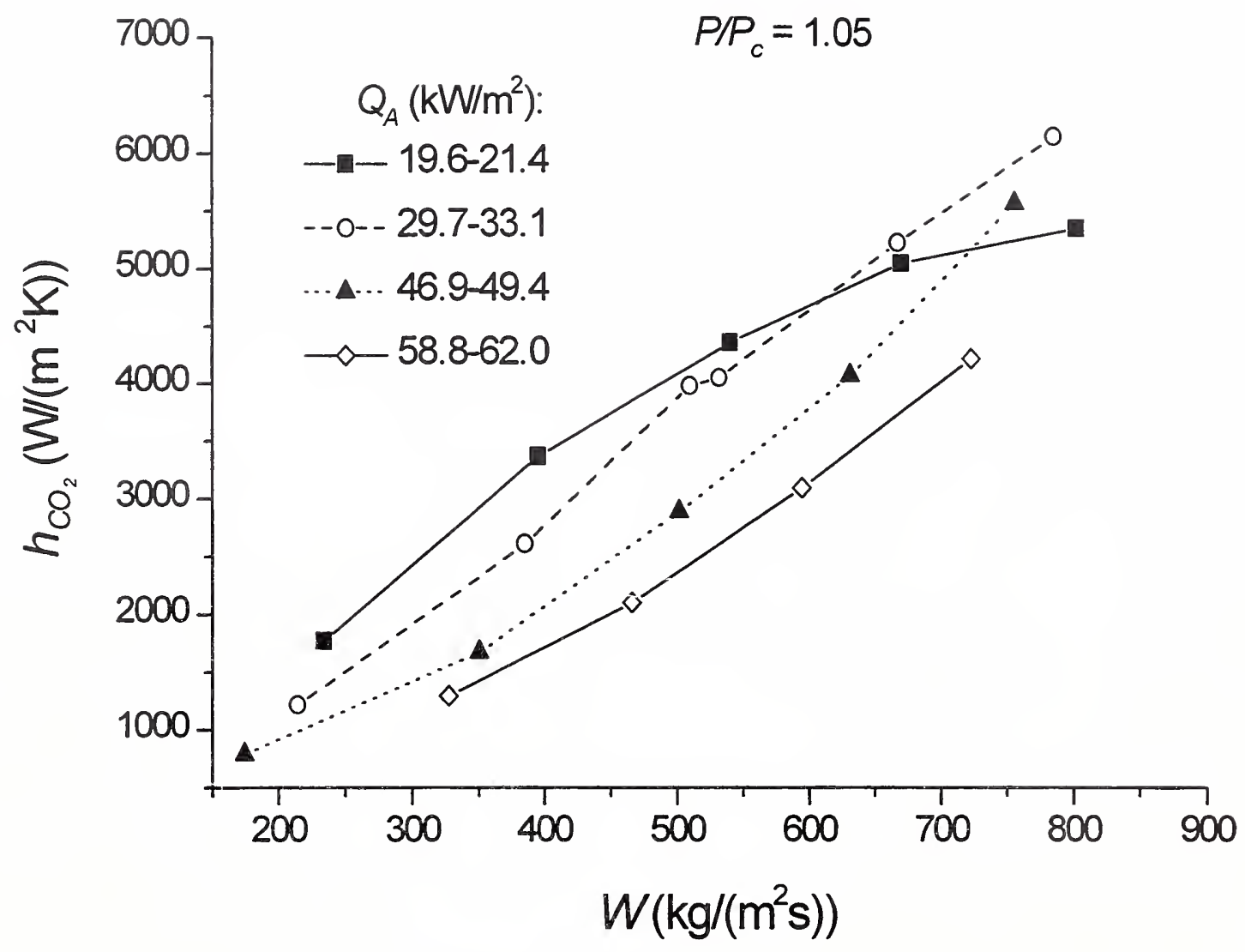

Figure 9. $\quad \mathrm{CO}_{2}$ heat transfer coefficient $(h)$ as a function of mass flux $(W)$ for several values of heat flux $\left(Q_{A}\right)$ at a pressure of $P / P_{c}=1.05$. 


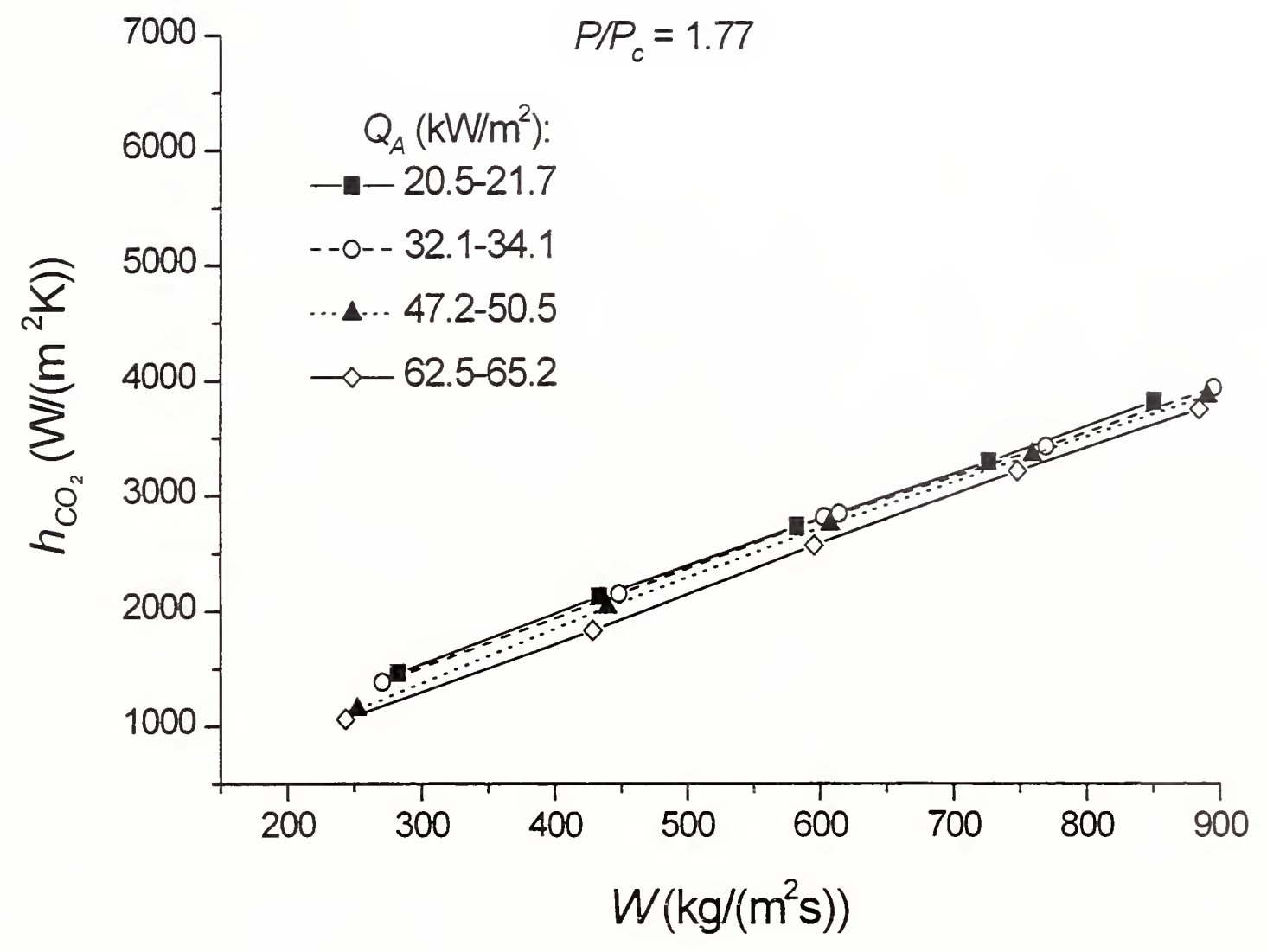

Figure 10. $\quad \mathrm{CO}_{2}$ heat transfer coefficient $(h)$ as a function of mass flux $(W)$ for several values of heat flux $\left(Q_{A}\right)$ at a pressure of $P / P_{c}=1.77$. 


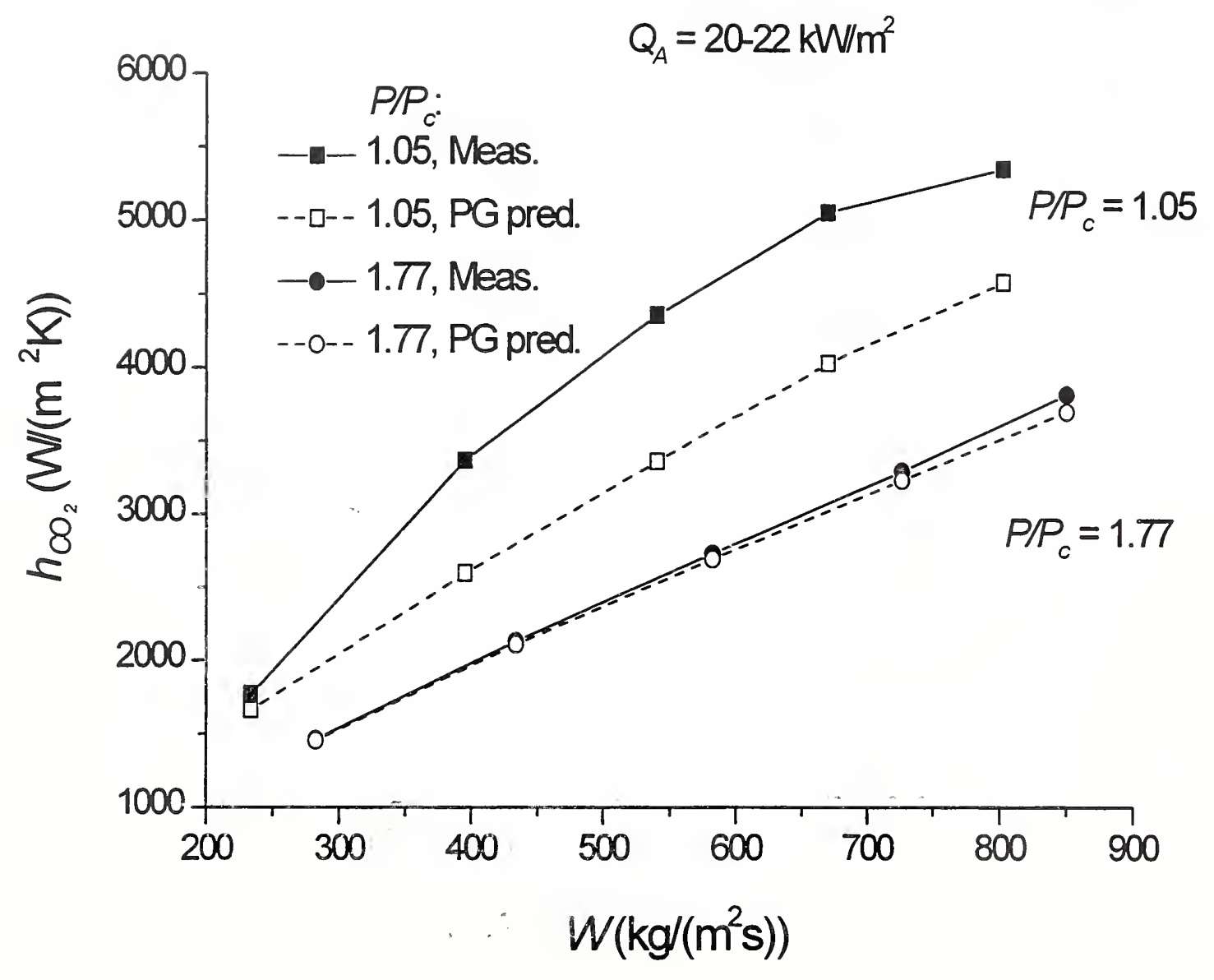

Figure 11. Comparison of measured $\mathrm{CO}_{2}$ heat transfer coefficient $(h)$ to that predicted by Petukhov-Gnielinski correlation, as a function of mass flux $(W)$, for $Q_{A}=20 \mathrm{~kW} / \mathrm{m}^{2}$ to $22 \mathrm{~kW} / \mathrm{m}^{2}, P / P_{c}=1.05$, and $P / P_{c}=1.77$. 


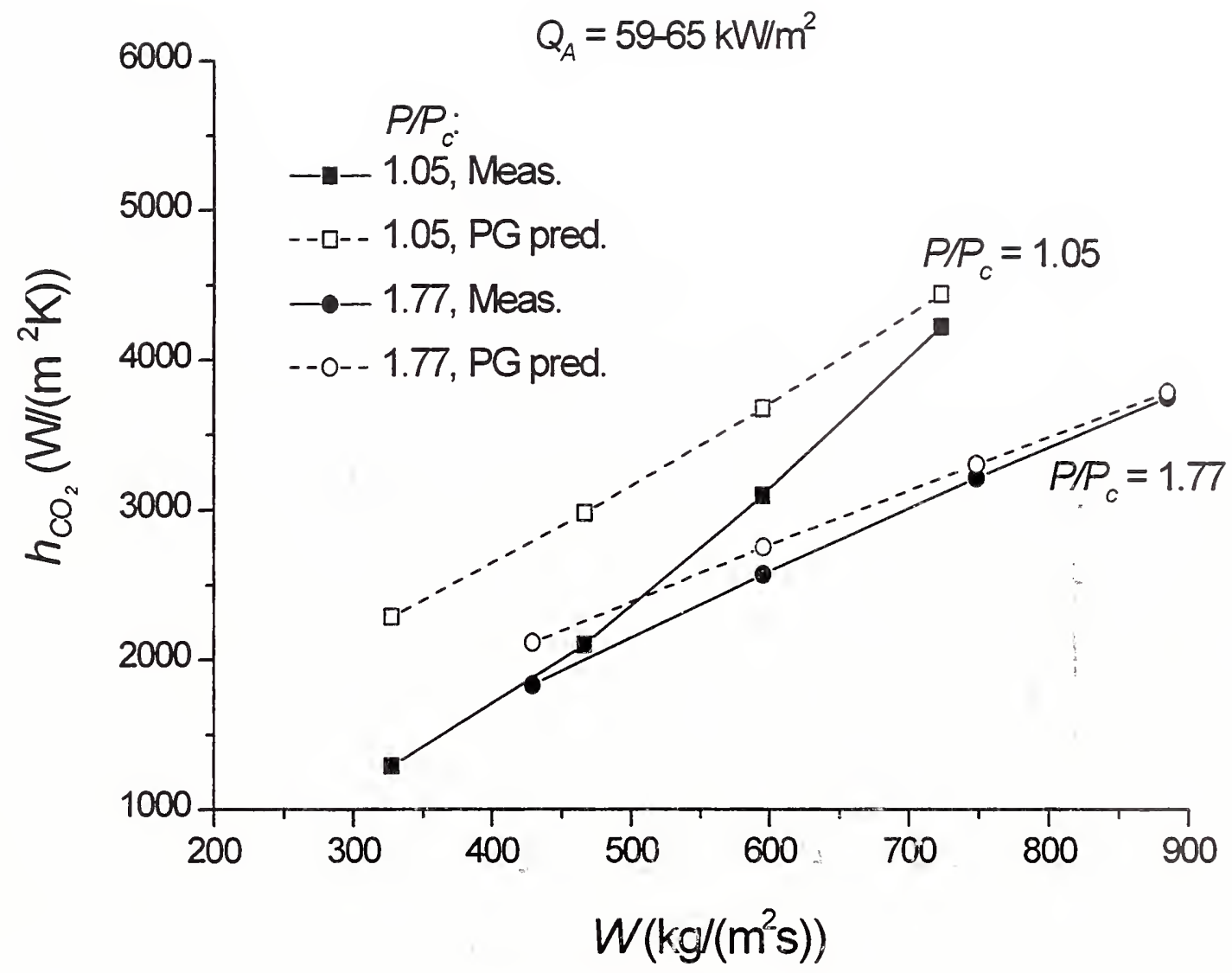

Figure 12. Comparison of measured $\mathrm{CO}_{2}$ heat transfer coefficient $(h)$ to that predicted by Petukhov-Gnielinski correlation, as a function of mass flux $(W)$, for $Q_{A}=59 \mathrm{~kW} / \mathrm{m}^{2}$ to $65 \mathrm{~kW} / \mathrm{m}^{2}, P / P_{c}=1.05$ and $P / P_{c}=1.77$. 


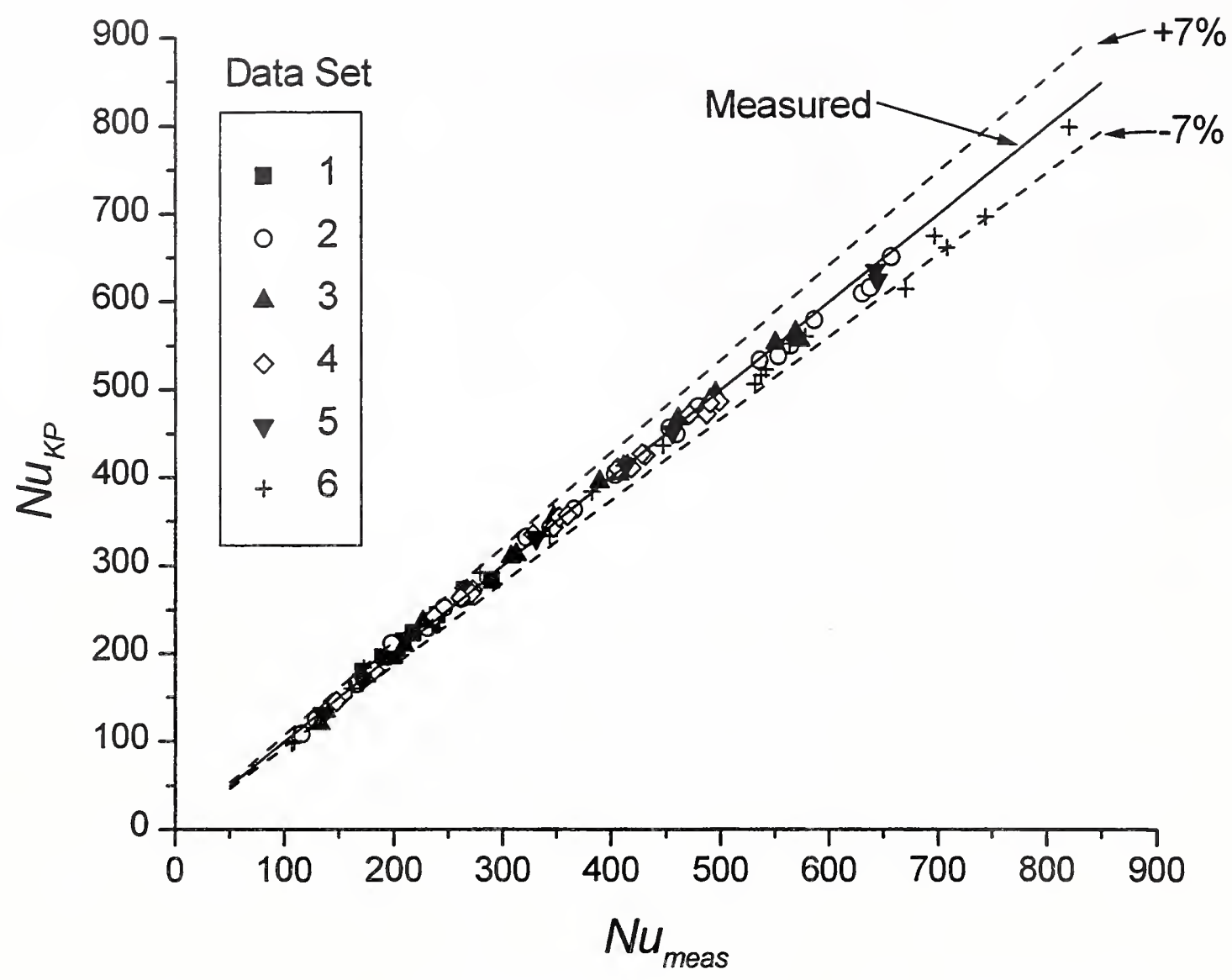

Figure 13. Comparison of Nusselt number predicted by Krashnoschekov-Protopopov correlation $\left(N u_{K P}\right)$ to the measured value $\left(N u_{\text {meas }}\right)$ for all experimental data. $\pm 7 \%$ deviation lines shown for comparison. 
NISTIR 6234

Data Tables, Experiments 1 to 6

D. Olson, Sept. 1998 
